Article

\title{
Rapid Assessment of Flood Inundation and Damaged Rice Area in Red River Delta from Sentinel 1A Imagery
}

\author{
Anh Phan ${ }^{1, * \mathbb{C} \text {, Duong N. Ha }}{ }^{1}$, Chuc D. Man ${ }^{1,2}$, Thuy T. Nguyen ${ }^{1}$, Hung Q. Bui ${ }^{1}$ and \\ Thanh T. N. Nguyen ${ }^{1}$ (D) \\ 1 Center of Multidisciplinary Integrated Technologies for Field Monitoring (FIMO), University of Engineering \\ and Technology, Vietnam National University Hanoi, 144 Xuanthuy, Hanoi 100000, Vietnam \\ 2 International Digital Earth Applied Science Research Center, Chubu Institute for Advanced Studies, \\ Chubu University, 1200 Matsumoto-cho, Kasugai, Aichi 487-8501, Japan \\ * Correspondence: anhp@fimo.edu.vn; Tel.: +84-354393959
}

Received: 26 June 2019; Accepted: 23 August 2019; Published: 29 August 2019

\begin{abstract}
The Red River Delta (RRD), including 11 provinces, is one of the four largest rice-growing areas in Vietnam. Tropical storms often occur and cause serious flooding from May to October annually in the RRD, which strongly affects the productivity of the summer-autumn rice, one of two main rice crops. Therefore, the rapid assessment of damaged rice area by flooding inundation is critical for farmers and the government. In this study, we proposed a methodology for quick estimation of rice areas damaged by flooding using Sentinel 1A (S1A) imagery. Firstly, the latest rice map was produced. Then, a Near Real-Time (NRT) flood map, which is estimated from S1A images at the closest time to a flooding event, was generated by excluding the yearly permanent map from the temporal water map. Our experiment was conducted for the assessment of damaged rice area by flooding from the tropical storm named Son-Tinh, which happened on 19-21 July 2018. A Support Vector Machine (SVM) classifier was applied on time-series of S1A VV with VH data (VVVH) to obtain a rice map for the winter-spring season of 2018 with 90.5\% Overall Accuracy (OA) and 2.37\% difference (12,544 ha) from the General Statistics Office (GSO) of Vietnam's reports for the whole region. Then, the Otsu thresholding method was applied for permanent water surface extraction and NRT flood mapping. The estimated damaged area was compared to available provincial and communal statistics for validation and further analysis. Right after the Son-Tinh storm, the estimation of inundated rice was approximately $50 \%$ of the total rice area in the RRD $(271,092 \mathrm{ha})$. As a result, rice damage level strongly corresponds to the inundation period. In addition, the rice-flooding frequency map over the RRD was estimated to show rice fields suffering a high risk of flooding during the rainy season in the RRD. Our experiment's results highlight the potential of using Synthetic-Aperture Radar (SAR) imagery for fast monitoring and assessment of paddy rice areas affected by flooding at a large scale in the RRD region.
\end{abstract}

Keywords: rice mapping; flood mapping; damage assessment; Red River Delta; Sentinel 1A

\section{Introduction}

\subsection{Rice and Flood in the Red River Delta}

Rice is one of the five main food crops for humans, along with corn, wheat, cassava and potatoes. Rice is considered a staple food for more than half of the world's population, especially in Asia and Latin America. Vietnam is a major rice exporter in the Asian region with an old rice farming industry and most of the region's rice fields from North to South. Vietnam's annual rice exportation accounts 
for $15 \%$ of the total rice volume worldwide [1]. In 2016, Vietnam continues to be the third-largest rice exporter in the world, after Thailand and India [2]. Vietnamese rice is available in nearly 150 countries and territories according to the Ministry of Industry and Trade (MOIT), in Vietnam [1].

The Red River Delta (RRD) is one of the four plains with the largest rice-growing area in Vietnam (see Table 1). On average, the RRD suffers about 4 storms a year from the South China Sea, which cause heavy rainfall in high mountainous and delta areas from May to October [3]. As a result, large floods occur frequently. During the flooding season, precipitation contributes to $70 \%$ of total water for the whole year. The causes of flooding in the RRD region are contributed to by storms both downstream and upstream of Red River, serious deforestation at the watershed [4], weakness of current dyke and drainage systems [5], and a fast urbanization rate [6]. Flooding has strong effects on rice production in the RRD each year. In 2018, crops in the Northern provinces suffered from complicated weather conditions which are a prolonged hot sunshine season causing cultivation difficulties and heavy rain for many days from the middle of July, and the tropical storm Son-Tinh [7]. The large flooding occurred and strongly affected new plants and crops.

Table 1. Rice production of the four largest rice areas in Vietnam (General Statistics Office (GSO)) [8].

\begin{tabular}{cccccc}
\hline \multirow{2}{*}{ Area } & \multicolumn{5}{c}{ Production (Thousands of Tons) } \\
\cline { 2 - 6 } & $\mathbf{2 0 1 3}$ & $\mathbf{2 0 1 4}$ & $\mathbf{2 0 1 5}$ & $\mathbf{2 0 1 6}$ & $\mathbf{2 0 1 7}$ \\
\hline Red River Delta & 6655 & 6759 & 6729 & 6545 & 6083 \\
Northern Midlands and Mountainous & 3265 & 3341 & 3336 & 3405 & 3336 \\
North Central Coast & 6599 & 7034 & 6855 & 6842 & 6997 \\
Mekong River Delta & 25,021 & 25,245 & 25,583 & 23,831 & 23,633 \\
\hline
\end{tabular}

\subsection{Monitoring Rice and Flooding Using Satellite Images}

Estimation of rice damaged by flooding is a difficult task in the field. With advantages from satellite technology, high-resolution satellite images have been utilized for a timely and complete assessment of flood inundation and the affected rice area.

Rice mapping has been undertaken since the late 1990s, using both radar and optical satellite images and following different approaches which include thresholding based on rice phenology analysis and machine learning (ML). Paddy rice growing stages consist of seeding, transplanting, tillering, flowering and harvesting, which determine the unique rice phenology. Based on the rice phenological analysis, the thresholding approach identifies values for specular satellite signal reflections or indicators in time-series to distinguish rice from other objects. Data from the Landsat TM and Japanese Earth Resources Satellite 1 (JERS-1) and the European Remote-Sensing Satellite (ERS-1) were analyzed to create rice maps over Indramayu in Indonesia [9] and the Mekong Delta region in Vietnam [10], respectively. In other studies, Normalized Difference Vegetation Index (NDVI), Enhanced Vegetation Index (EVI), Vegetation Index (VI), Normalized Difference Water Index (NDWI), Normalized Difference Snow Index (NDSI) were used to improve the quality of the rice maps [11]. Those indicators were calculated from Moderate Resolution Imaging Spectroradiometer (MODIS) data and applied corresponding thresholds based on rice phenological analysis to create rice maps in References [12-15]. Thresholding based on phenology analysis requires solid background knowledge of rice cultivation, satellite signals and indicator characteristics and adjustment for regional environmental conditions. Recently, the ML approach has been applied widely since its performance might surpass the traditional thresholding method [16]. Both supervised and unsupervised ML models were implemented for classification and clustering, respectively. The ML approach is easy and convenient for fast implementation but it requires strong data features for training classifiers. Optical spectral reflectance [17-20], indicators such as NDVI, NDWI [18], and SAR backscattering coefficients [18] have been used as features for ML models. Regarding ML techniques, SVM [16,18,21], Random Forest (RF) $[18,22]$ and K-mean $[19,20]$ were largely used for rice mapping. 
In Vietnam, rice mapping from satellite images was mostly applied in the Mekong River Delta where the biggest rice cultivation area is. Sakamoto et al. used MODIS data over 7 years for the classification of aquaculture surfaces and rice-growing areas in three seasons in Soc Trang and Bac Lieu provinces. In the study, wavelet-based filter and thresholding of EVI, Land Surface Water Index (LSWI), and Difference Value between EVI and LSWI (DVEL) indicators were applied for rice classification [23]. Another study of rice mapping was carried out using the thresholding method on EVI derived from MODIS imagery [24]. In order to capture a variety of customized cultivation by location, Kontgis et al. proposed a mean-shift segmentation algorithm to set different thresholds of EVI estimated from Landsat data for single-, double- and triple-cropped fields [25]. Also, time-series of An Advanced Synthetic Aperture Radar (ASAR) images were used to map early rice, late rice and double-crop using the thresholding technique [26]. Nguyen et al. also used multi-temporal ASAR data to develop a knowledge-based decision-tree to determine rice crop based on its seasonal spectral signature [27]. Some rice mapping studies have been conducted in the Red River catchment. Hoang et al. used RADARSAT-2 dual-polarization data with the threshold-based approach and quad-polarization data with an SVM classifier for rice mapping in the Cau River Basin [16]. A combination of data from Landsat-8, Sentinel-1A and PALSAR-2 data was utilized to produce a rice map using a Random Forest (RF) classifier for greenhouse gas emission evaluation in the RRD [28]. Due to the high frequent cloud cover in this area, Chuc et al. proposed a compositing method for Landsat-8 images, which is used for rice mapping with XGBoost classifier later [29]. Other studies utilized time-series SAR imagery for rice classification using ML techniques including SVM [30,31], Simple Linear Iterative Clustering super-pixel algorithm [32], decision tree based on phenology analysis and the thresholding approach [33]. We found that the rice map of all 11 provinces in the RRD area has not been noticed due to the confusion in available administrative maps in previous studies.

The growth process of rice is strongly associated with the irrigation schedule. At the beginning of the rice crop cycle, water is poured into the paddy field, which makes the vegetation indices (NDVI, EVI) decrease and water indices (LSWI, NDWI) increase and similarly changes SAR backscatter coefficients. The flooding causes the same spectrum change as irrigated rice fields. However, the occurrence time of these phenomena is different, so this time characteristic is used to distinguish (NRT) floods and seasonal irrigation.

The flood detection methods are divided into three main categories: (1) thresholding techniques [34-41]; (2) complex prediction models [42-44]; and (3) ML approach [45-48]. In particular, thresholding techniques are mainly applied for NRT flood detection including adaptive thresholding [36-39] and fixed thresholding [34,35,40,41,49] techniques. Fixed thresholding is often used based on expert knowledge from optical satellite-derived indices (NDVI, NDWI, LSWI, NDSI). Meanwhile, the adaptive method is mainly based on the bimodal distribution histogram of the grayscale image or maximum variance between classes (or minimum variance within classes) of a grayscale image to separate flooding from others. This method is commonly applied for SAR imagery. The adaptive thresholding technique is selected in this study since its good performance and accuracy were proved for NRT flood mapping in previous studies. Recently, social media data has also been used to detect rapid flooding [50,51]. Adaptive thresholding techniques have some drawbacks in finding an optimal threshold [52]. Several studies have been proposed to improve the performance of the thresholding approach-using unsupervised fuzzy classification [52], split-based approaches [36,39], a combination of different methodologies and multisource data [53]. The combination of NRT flood maps and rice maps might help with the assessment of the affected rice area. In previous studies, MODIS data was also used to evaluate flooding damage to rice in the Chao Phraya Delta region in Thailand [40] and Cambodia [41,54], although MODIS has a low spatial resolution, is affected by environmental conditions and may cause high errors in flood mapping. In addition to the above studies, NRT flood mapping services were also available and provided by the National Aeronautics and Space Administration (NASA) [55] and Copernicus Emergency Management Service-Mapping [56]. 


\subsection{Contribution and Structure of the Article}

The RRD is a major granary in Vietnam but is strongly affected annually by flooding from May to October. Until now, in the RRD the most common way to assess rice damage caused by flooding is based on GSO statistics. However, the statistical report is not updated in real-time, meanwhile, the effectiveness of satellite imagery for rice mapping and NRT flooding monitoring has been proved. In this study, we proposed a method for the rapid assessment of flood inundation and the affected rice area in the RRD using S1A imagery. An experiment was carried out using data from the tropical storm Son-Tinh in July 2018. We firstly produced the rice map in the winter-spring season, and flood maps caused by the Son-Tinh storm. The affected rice area was estimated by the timely analysis of flood maps on the rice map. After that, statistical reports for rice damage by inundation from the Vietnamese GSO were used to assess the accuracy of our proposed method. To our best knowledge, this study is the first work on the rapid assessment of affected rice areas caused by flood inundation for the RRD region using S1A images. The damage can be assessed in NRT at high spatial resolution (i.e., $10 \mathrm{~m}$ ). The good evaluation results in comparison with GSO reports have highlighted the potential application aspects of the proposed method. In the next section, the study area and datasets will be presented. The methodology of the proposed method will be described in Section 3. The experimental results, accuracy assessment and further analysis will be presented in Section 4. Finally, Section 5 presents the conclusions and future work.

\section{Study Area and Dataset}

\subsection{The Red River Delta}

The Red River Delta is made up of the Red River system and the Thai Binh River system (Cau River, Thuong River, and Luc Nam River) with an area of approximately $15,000 \mathrm{~km}^{2}$ extending from Quang Ninh to Ninh Binh (see Figure 1). Currently, there are two main rice seasons in the RRD which are the winter-spring season (February to June) and the summer-autumn season (July to November). The winter-spring season is often cultivated in the dry season, so active irrigation water is required. Spring rice (i.e., early spring-, main season-, late spring-rice) is often cultivated at the end of the last November to March and harvested in June. The summer-autumn season starts in late May to July and ends in mid-November.

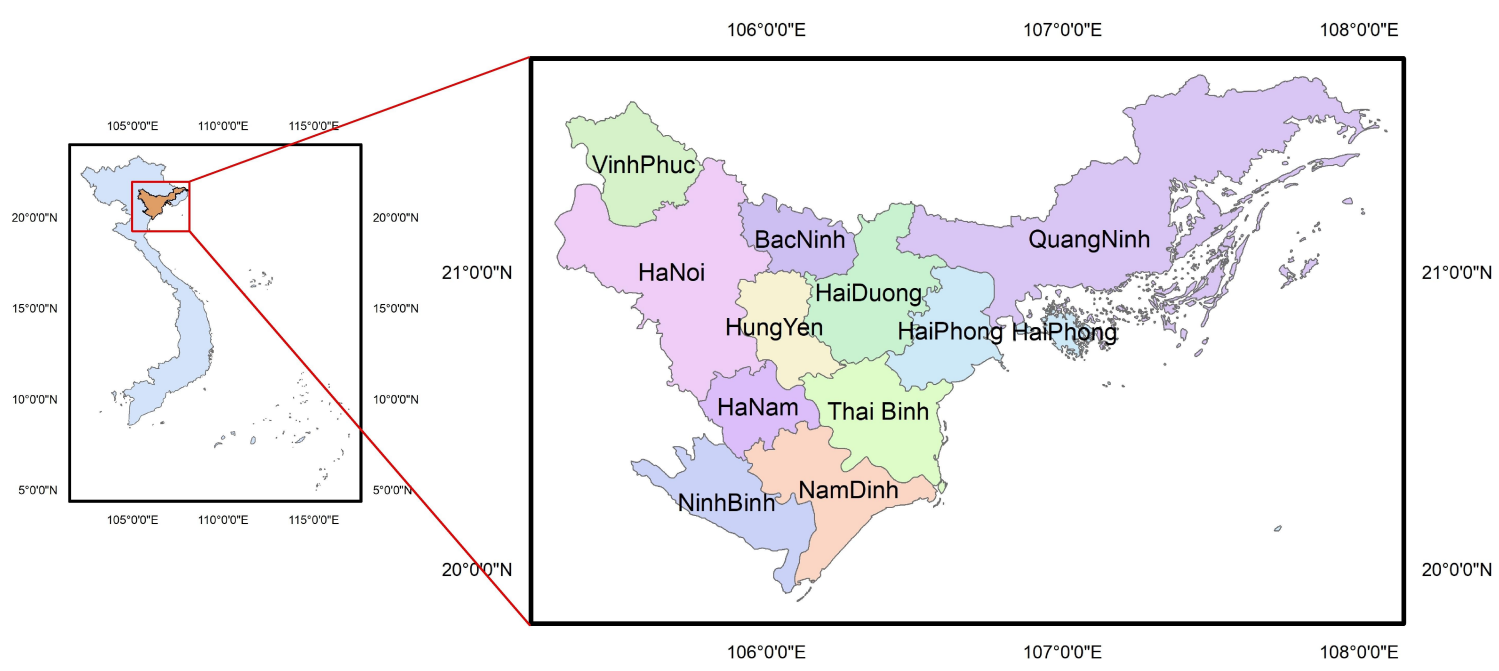

Figure 1. Administrative map of the Red River Delta over Vietnam. 


\subsection{Sentinel $1 A$}

Sentinel 1 is a satellite constellation from the European Space Agency (ESA). Sentinel 1 includes two satellites-Sentinel $1 \mathrm{~A} / \mathrm{B}$ - that carry C-band SAR imagery with a 6-day revisit with the availability of both satellites only in Europe and in some other limited areas while in the rest of the world, the images are provided every 12 days. Sentinel 1 provides dual-polarized Interferometric Wide (IW) swath data with Vertical Transmit-Vertical Receive (VV) and Vertical Transmit-Horizontal Receive $(\mathrm{VH})$ polarizations data. IW swath mode features $5 \times 20 \mathrm{~m}$ spatial resolution and a $250 \mathrm{~km}$ swath. S1A images used in the study are shown in Table 2. In particular, all S1A Level-1 Ground Range Detected (GRD) images in 2018 were used for permanent water mapping. Ten S1A-GRD images between 1 February 2018 and 31 May 2018, were used to produce the rice map for the winter-spring season 2018. Nine S1A-GRD images from 1 July 2018 to 30 October 2018 were used to generate flood maps and the flood frequency map. Four S1A scenes were requested and mosaicked to fully cover the whole RRD region, in which two scenes with Relative Orbit Number (RoN) of 55 cover Quang Ninh and two other scenes with RoN of 91 cover the rest.

Table 2. S1A data used in the study.

\begin{tabular}{cccccc}
\hline Duration & RoN & Number of Images & Channel & Product Type & Tasks \\
\hline 1 February 2018-31 May 2018 & 91 and 55 & 10 & VV, VH & GRD & Rice mapping for winter-spring season \\
1 January 2018-31 December 2018 & 91 and 55 & 31 & VV & GRD & Permanent water map \\
1 July 2018-30 October 2018 & 91 and 55 & 9 & VH & GRD & Flood map and flood frequency map \\
\hline
\end{tabular}

\subsection{Reference Data}

More than 150 locations were randomly selected for the training dataset based on the RRD land use map of 2012 with the proportion of 75 locations for rice and 75 locations for non-rice areas. The testing dataset, based on an integrated sampling of two-stage cluster sampling and stratified sampling, includes 549 points for rice and 849 points for non-rice (Figure 2a). Stratified sampling was adapted at the provincial level. Cluster sampling was used at the district and commune level to select randomly sampled locations. There was no overlap between the training and test samples. Training and test data were labeled using very high resolution (VHR) satellite images derived from Google Earth. In the RRD, permanent water was grouped mainly into two types of regular water surface and aquaculture. To assess the quality of permanent water maps, 362 locations were randomly selected by a stratified sampling method for two strata with a confidence level (CL) of $95 \%$ and confidence interval (CI) of $5 \%$ for regular water surface and aquaculture. Also, 500 points for non-water areas were selected (Figure 2b). The data were also labeled based on VHR satellite images from Google Earth. GSO statistical data of rice area at the provincial level in the RRD for the 2018 winter-spring season were used to assess the quality of the rice map. The quality of the flooding maps was assessed by GSO inundated rice areas of provinces and cities which were seriously affected by the tropical storm Son-Tinh, such as Bac Ninh (Tien Du, Thuan Thanh and Luong Tai), Thai Binh (Tien Hai, Thai Thuy and Kien Xuong), Nam Dinh, Ha Noi, and Ninh Binh. 


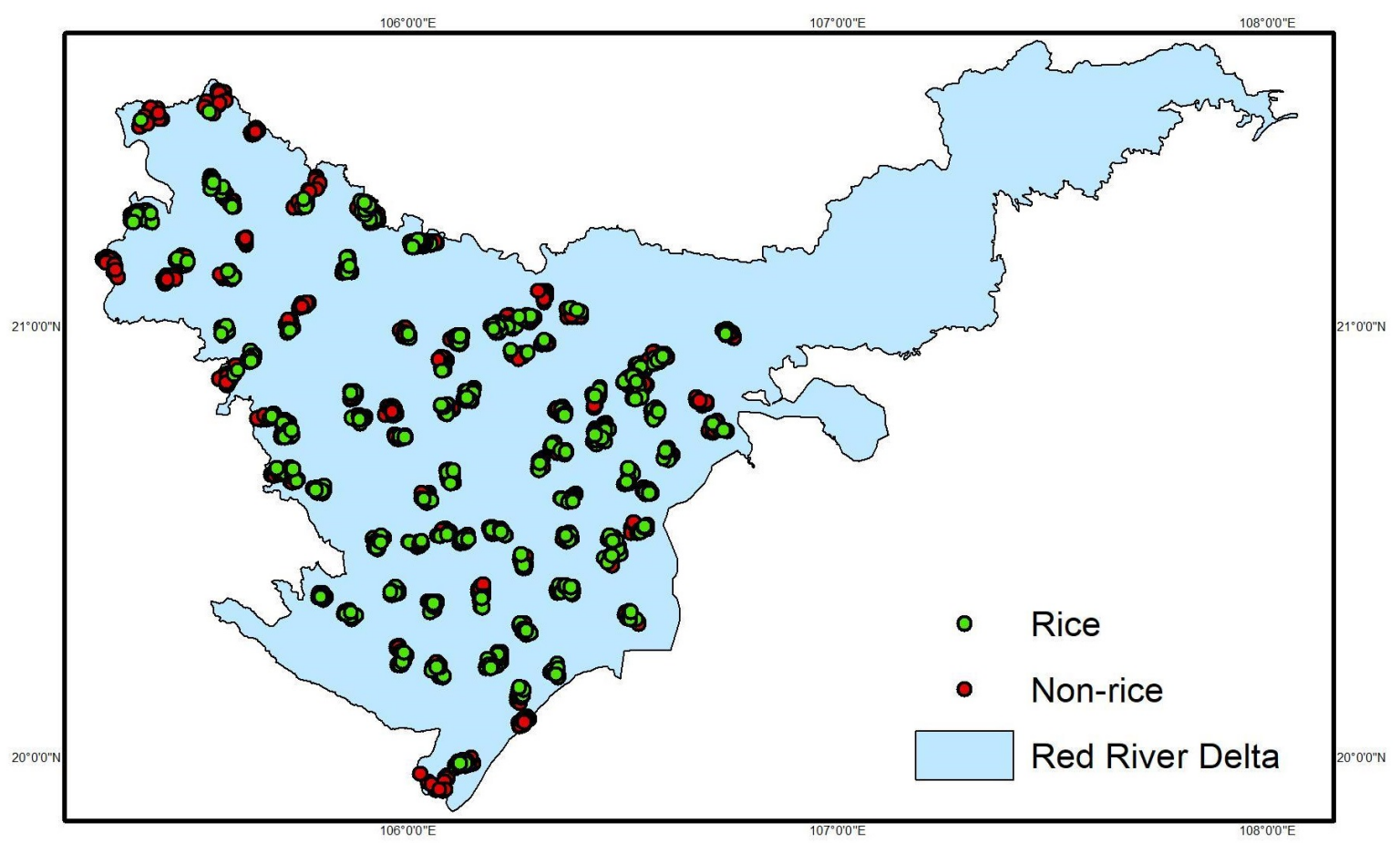

(a)

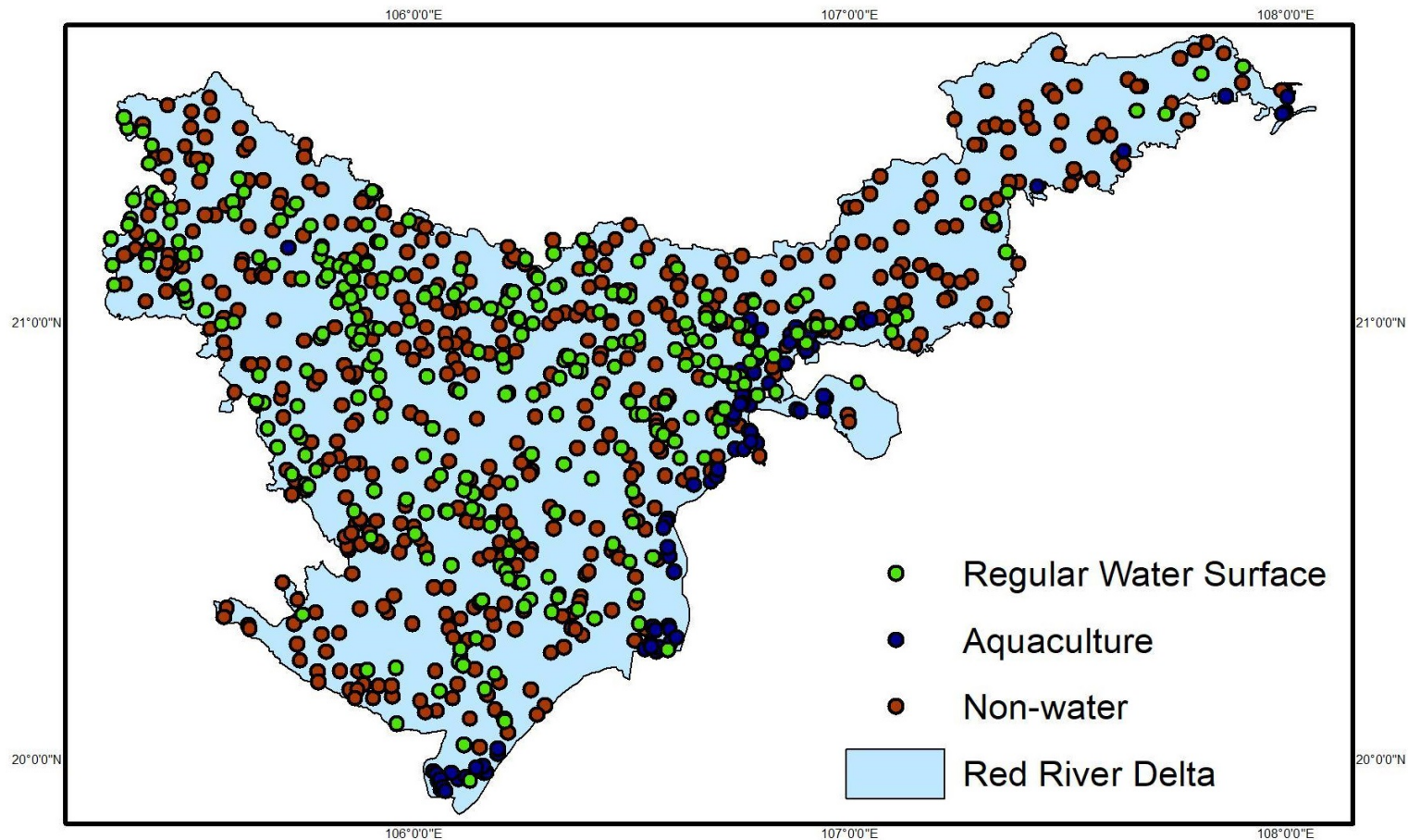

(b)

Figure 2. Validation datasets for (a) rice mapping and (b) permanent water mapping.

\section{Methodology}

The proposed method consists of three main components including rice mapping for the latest season, NRT flood mapping and affected rice assessment as shown in Figure 3. The details are described as follows. 


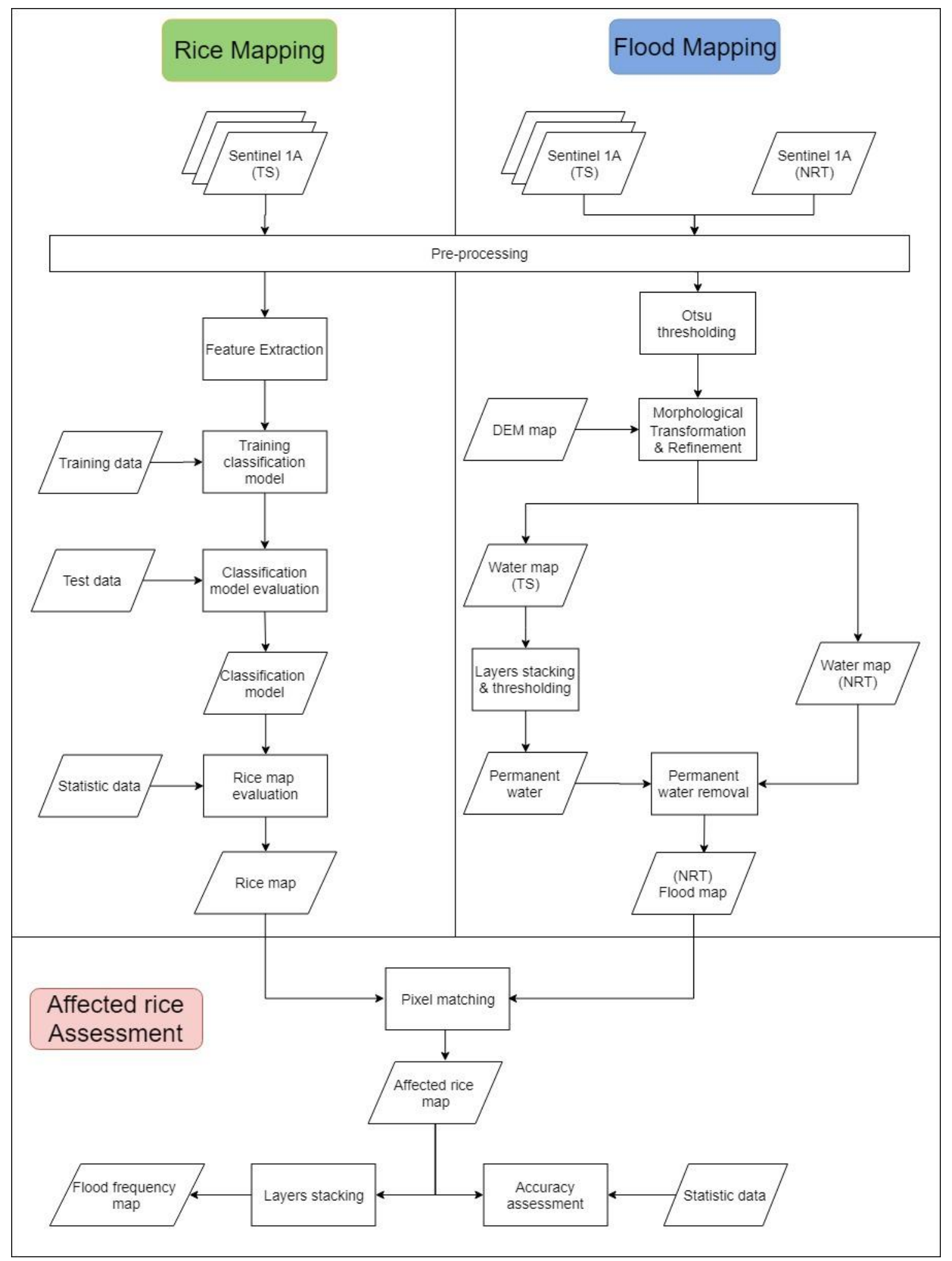

Figure 3. Overall flow chart of the study methodology.

\subsection{Rice Mapping}

Firstly, SAR data were pre-processed for thermal noise removing, radiometric calibration and geometric terrain correction. Thermal noise is additional background energy caused by microscopic motions of electrons due to temperature. SAR backscatter values were adjusted by radiometric calibration, meanwhile, effects of side-looking geometry were removed by geometric terrain correction. 
In this study, SAR imagery pre-processing was rapidly implemented using the Google Earth Engine. After that, the processed S1A data was sampled at $10 \mathrm{~m}$ resolution, in which each S1A image contained $\mathrm{VV}$ and $\mathrm{VH}$ bands. The feature extraction step created four time-series datasets- $-\mathrm{VV}, \mathrm{VH}, \frac{V V-V H}{V V+V H}$ and VVVH to train classification models and test their qualities.

SVM is a supervised machine learning model which has been widely applied in remote sensing and land-cover mapping in particular [57]. The SVM classifier was selected because it was originally designed for binary classification [58] and also due to the good performance of rice classification of the previous studies in rice mapping $[11,12,25,59]$. The model parameters (penalty $C$ and gamma) were optimized with kernel function Radial Basis Function (RBF) using cross-validation to reach the best performance of classification $[18,60]$. In this study, data from 75 locations were used for training classification models. In total, four classifiers were trained with corresponding features including $\mathrm{VV}, \mathrm{VH}, \frac{V V-V H}{V V+V H}$ and $\mathrm{VVVH}$. They were evaluated with independent testing datasets and statistical provincial data based on OA, F1-score (F1) and Kappa score (Kappa). Python programming language with Scikit-learn machine learning library was used for the implementation.

\subsection{Flood and Permanent Water Mapping}

All S1A images in the year of 2018 were collected to determine permanent water surface while a NRT S1A image during or after heavy rain was processed to create the NRT flood map. All S1A images were pre-processed by a similar procedure to that mentioned in Section 3.1. The VV channel was first evaluated with $\mathrm{VH}$ and then used for permanent water mapping [61]. Meanwhile, $\mathrm{VH}$ data were utilized for flood mapping because they are more sensitive than the VV channel for plant surface. When flooding occurs, the backscatter coefficient value of the VH channel will significantly decrease compared to the backscatter coefficient value of the plant surface [62].

The Otsu thresholding method was adapted to distinguish the water surface from other surfaces [63]. The Otsu algorithm is a binary classification algorithm, which performs a comparison of all pixel values of a grayscale image with a threshold value. Pixels with values less than the threshold will be assigned to the background layer, while the others are classified as the foreground class. The idea of the Otsu algorithm is to find this threshold automatically when the within-class variance is minimal or between-class variance is maximal. After the temporal water map was calculated by adapting the Otsu method, morphological transformation techniques including an opening and closing operations were performed [64]. In particular, the opening transformation was applied to remove noises while closing transformation closes small holes or removes small points inside the object. In some high-mountain forest areas (the North region of Vietnam), the terrain shadows in some areas confuse with the surface water due to its low backscatter values. Therefore, a Digital Elevation Model (DEM) map was used to remove hilly areas that were misclassified into water surfaces. An empirical threshold was selected for the DEM map to differentiate the valley area which is affected by high mountain shadow. In this study, we used the DEM Shuttle Radar Topography Mission (SRTM) map from the U.S. Geological Survey (USGS) [65] with a spatial resolution of $30 \mathrm{~m}$. Based on temporal water maps, permanent water, such as rivers, big lakes and watercourses, was extracted. If a pixel was classified as water for every single image in a month, it was labeled as permanent water for that month only. This process was repeated for available S1A data in 12 months of 2018 respectively to produce 12 monthly permanent water maps. Flooding was assumed to be a phenomenon of water surfaces appearing in a short time, while permanent water oppositely holds water for a long time. Flood maps would be obtained by excluding permanent water pixels from a temporal water map any time. The flood mapping process was deployed using a cloud computing platform provided by the Google Earth Engine.

\subsection{Affected Rice Area Assessment}

After the rice and flood maps were obtained, pixel matching was performed to determine the affected rice map. A pixel was considered as affected if it was in both the rice and flood map. 
The time-series of affected rice maps for the whole season were stacked to calculate a flood frequency map which was used to visually assess severely affected areas and flooding risk. The affected rice map was analyzed and evaluated mainly based on statistical reports from GSO for the provinces that were most affected during the storm Son-Tinh. The flood frequency map was visually inspected at some heavily affected sites (Bui River dyke in Chuong My [66], Nho Quan-Ninh Binh [67], Nam Dinh).

\section{Experimental Result and Discussion}

The tropical storm Son-Tinh hit the RRD in July 2018. It was a deadly storm that devastated the RRD and caused severe flooding and landslide, leading to the death of people. Thousands of hectares of agricultural crop were inundated and swept away. Therefore, in this study, we applied the proposed method to assess flood inundation and affected rice in the summer-autumn season of 2018.

\subsection{Phenology Analysis Based on Backscatter Coefficients}

We selected a test dataset with the distribution shown in Figure 4 for phenology analysis based on the land-use map of the RRD in 2012. Data, collected in the year of 2018, includes 7, 4, 8, 6, 10 points for water, bare land, urban, rice and forest, respectively. The time-series of backscatter coefficients for land classes are presented in Figure 5.

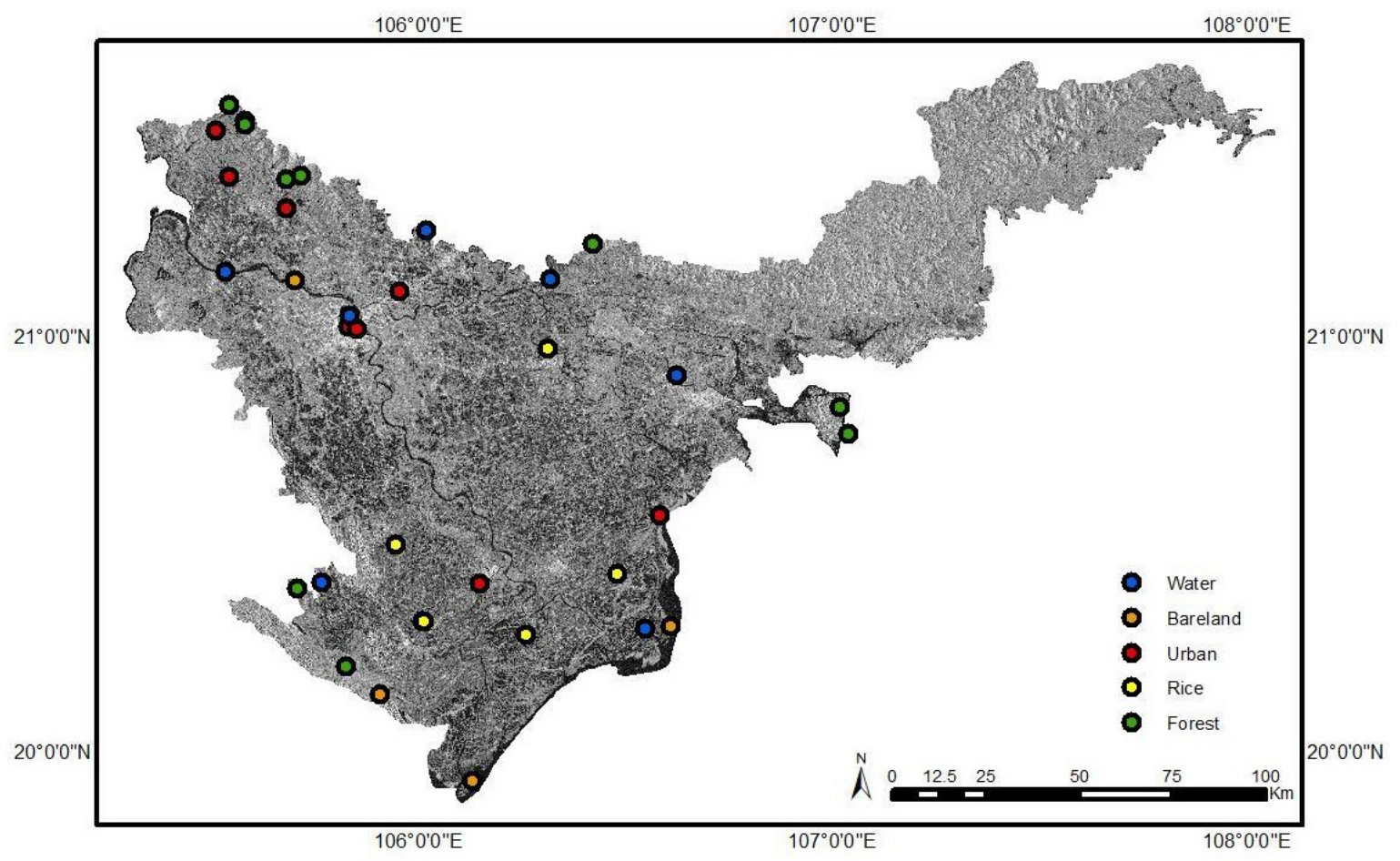

Figure 4. Test sizes for phenology analysis in the Red River Delta (RRD).

It was observed that the average backscatter coefficients of urban and forest areas remain high and stable with low standard deviation. Backscatter values in urban areas are in the range of -12.47 to $-11.45 \mathrm{~dB}$ for the $\mathrm{VH}$ channel and -4.92 to $-3.32 \mathrm{~dB}$ for $\mathrm{VV}$ channel. Meanwhile, the backscatter coefficient of the forest is slightly slower in a range of -14.8 to $-13.3 \mathrm{~dB}$ with $\mathrm{VH}$ channel and -8.67 to $-7.24 \mathrm{~dB}$ with VV channel. Bare land has lower backscatter values in comparison with urban and forest (i.e., -19.3 to $-15 \mathrm{~dB}$ for $\mathrm{VH}$ and -12.6 to $-9 \mathrm{~dB}$ for VV). Entirely bare soil will have stable backscatter values but these areas may include grass and wild plants which make unstable signals sometimes. Besides, some bare land areas at low elevation may be temporarily inundated if heavy rains occur. The bare land's backscatter value was sharply reduced on 22 July 2018, when there were heavy rains caused by the Son-Tinh storm (see Figure 5). Because of changes in the bare land surface, its standard deviation value is slightly higher than the standard deviation of forest 
and urban classes. Regarding paddy rice, there is an extremely large change in backscatter signals during its growth, which is presented by the high standard deviation from $3.67 \mathrm{~dB}$ with $\mathrm{VH}$ and $2.6 \mathrm{~dB}$ with VV. Based on this time-series characteristic, rice might be separated from different land surfaces. Water is the layer with the lowest backscatter average from -28.5 to $-24.8 \mathrm{~dB}$ with $\mathrm{VH}$ and -21.3 to $-17 \mathrm{~dB}$ with VV. Therefore, both $\mathrm{VH}$ and VV can be used to distinguish water surface from other surfaces $[68,69]$. In addition, in the calm wind condition, radar signals may be considered as reflections causing low-intensity equivalent to the dark pixel in SAR imagery [70]. In this case, VV will give better accuracy than $\mathrm{VH}$ polarization [71]. The statistical backscatter coefficients of VV and VH channels are summarized in Table 3.

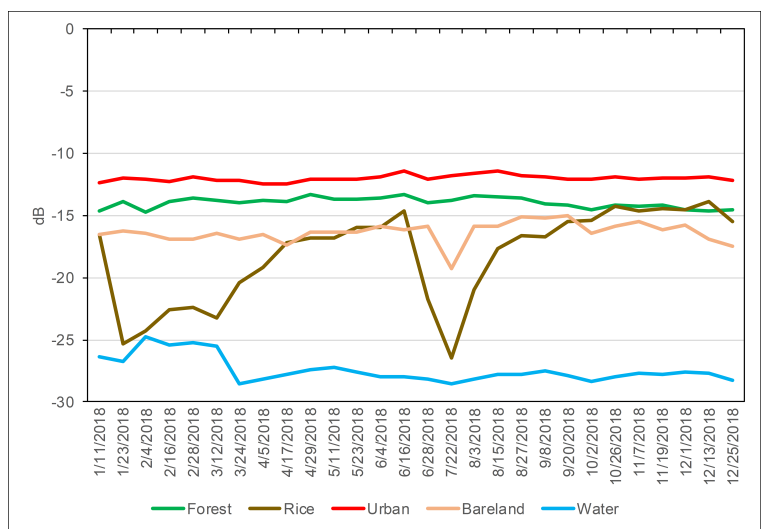

(a)

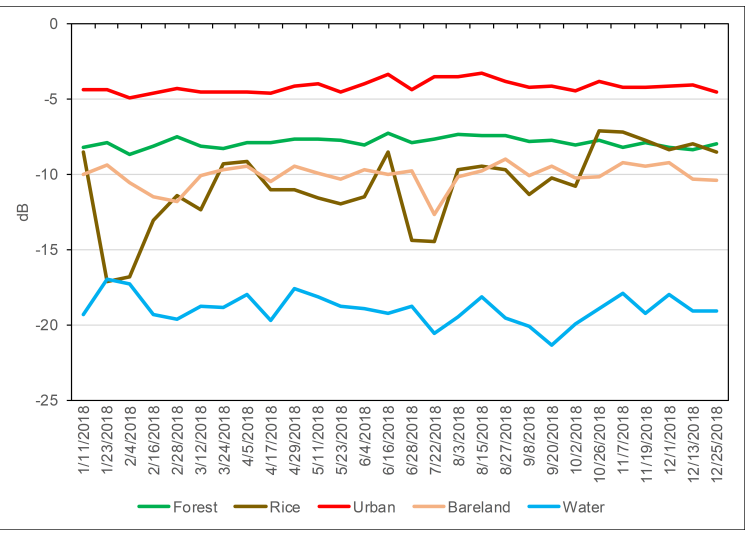

(b)

Figure 5. The average backscatter of 5 land-cover classes in the RRD. The VH-, and VV-average backscatter coefficient are respectively shown in $(\mathbf{a}, \mathbf{b})$.

Table 3. Statistical measures of VV and VH channels for different land surfaces.

\begin{tabular}{ccccccccccc}
\hline \multirow{2}{*}{ Class } & \multicolumn{2}{c}{ Mean } & \multicolumn{2}{c}{ STD } & \multicolumn{2}{c}{ Max } & \multicolumn{2}{c}{ Min } & \multicolumn{2}{c}{ Diff } \\
\cline { 2 - 11 } & $\mathbf{V V}$ & $\mathbf{V H}$ & $\mathbf{V V}$ & $\mathbf{V H}$ & $\mathbf{V V}$ & $\mathbf{V H}$ & $\mathbf{V V}$ & $\mathbf{V H}$ & $\mathbf{V V}$ & VH \\
\hline Forest & -7.89 & -13.97 & 0.33 & 0.41 & -7.24 & -13.29 & -8.67 & -14.77 & -1.43 & -1.47 \\
Rice & -10.73 & -18.21 & 2.60 & 3.67 & -7.11 & -13.89 & -17.16 & -26.46 & -10.06 & -12.57 \\
Urban & -4.20 & -12.02 & 0.40 & 0.25 & -3.32 & -11.45 & -4.92 & -12.47 & -1.60 & -1.02 \\
Bare land & -10.09 & -16.34 & 0.78 & 0.82 & -9.00 & -15.02 & -12.65 & -19.28 & -3.65 & -4.27 \\
Water & -18.95 & -27.43 & 0.96 & 1.01 & -16.97 & -24.76 & -21.37 & -28.56 & -4.40 & -3.80 \\
\hline
\end{tabular}

\subsection{Rice Mapping}

Ten S1A images with RoN of 55 acquired from 2 February 2018, to 21 May 2018 were used for rice mapping in Quang Ninh while 10 S1A images from 4 February 2018, to 23 May 2018, with RoN of 91, were used for the remaining 10 provinces. Four datasets of features $\mathrm{VV}, \mathrm{VH}, \frac{V V-V H}{V V+V H}$ and VVVH were investigated to develop the best classification model for rice mapping. We found that the VVVH temporal backscatter feature outperformed the rest of feature datasets with 5.43\% higher OA, $5.25 \%$ higher F1 score and 11.25\% higher Kappa coefficient on average (Table 4). Rice sensitivity is quite similar to $\mathrm{VV}$ and $\mathrm{VH}$ individually since the recalls of $\mathrm{VV}, \mathrm{VH}$ and $\mathrm{VVVH}$ are similar for rice $(0.84,0.85$ and 0.84 , respectively in Table 5). However, the usage of both VV and VH temporal data is better than any individual one in distinguishing rice from the other classes (i.e., the highest precision). The combination of two channels following equation $\frac{V V-V H}{V V+V H}$ resulted in the most ineffective with 6.67\% lower OA, 6.75\% lower F1 Score and 13.75\% lower Kappa coefficient. Thereby, time-series of VV and $\mathrm{VH}$ individually had good features that were even better when combined to classify rice. 
Table 4. Rice map classification evaluation over four feature datasets.

\begin{tabular}{cccccc}
\hline Data & OA(\%) & F1-Rice & F1-Non-Rice & F1-Average & Kappa \\
\hline VV Time-series & 82.90 & 0.77 & 0.86 & 0.83 & 0.64 \\
VH Time-series & 88.48 & 0.85 & 0.91 & 0.88 & 0.76 \\
$V V-V H$ \\
$V V+V H$ Time-series & 78.40 & 0.73 & 0.82 & 0.78 & 0.55 \\
VVVH Time-series & 90.50 & 0.87 & 0.92 & 0.90 & 0.80 \\
\hline
\end{tabular}

Table 5. Precision and recall for rice classification over four feature datasets.

\begin{tabular}{cccc}
\hline Data & Measures & Rice & Non-Rice \\
\hline \multirow{2}{*}{ VV Time-series } & Precision & 0.81 & 0.74 \\
& Recall & 0.84 & 0.89 \\
VH Time-series & Precision & 0.86 & 0.90 \\
& Recall & 0.85 & 0.91 \\
$\frac{V-V H}{V V+V H}$ Time-series & Precision & 0.71 & 0.83 \\
& Recall & 0.75 & 0.81 \\
VVVH Time-series & Precision & 0.91 & 0.90 \\
& Recall & 0.84 & 0.94 \\
\hline
\end{tabular}

The quality of the best rice map, produced by the VVVH dataset, was evaluated even further by comparison with statistics from the GSO at the provincial level (Table 6). The error of the whole region is approximately $2.37 \%,(12,544$ hectares). The estimated rice area is quite similar for most of the provinces in the RRD. However, rice maps in Quang Ninh cause the most differences (10,665 hectares). By visual inspection, we realized that in some high mountain areas like Quang Ninh, terrain shadow might be misclassified as rice. Figure 6 shows the strong agreement of estimated rice with GSO statistics in 11 provinces in the RRD with a high correlation coefficient at 0.97 . The entire rice map for the winter-spring crop in 2018 presents the popularity of rice in the RRD. However, Quang Ninh is the largest area $(610,200 \mathrm{ha})$ in the region but its rice area is the lowest one (see Table 6 and Figure 7). Rice is sparsely grown in hilly areas and islands compared to the plain.

Table 6. A comparison of rice area according to statistics and classification at the provincial level.

\begin{tabular}{ccccc}
\hline Province/City & Statistical Area (ha) & Predicted Area (ha) & Diff(ha) & Diff(\%) \\
\hline Thai Binh & 79,319 & 80,320 & 1001 & 1.26 \\
Quang Ninh & 16,500 & 27,165 & 10,665 & 64.64 \\
Vinh Phuc & 30,837 & 29,574 & -1263 & -4.09 \\
Bac Ninh & 37,890 & 34,306 & -3584 & -9.40 \\
Ha Noi & 93,314 & 90,675 & -2639 & -2.82 \\
Nam Đinh & 73,936 & 78,868 & 4932 & 6.67 \\
Ninh Binh & 40,600 & 44,615 & 4015 & 9.88 \\
Hai Phong & 34,163 & 34,355 & 192 & 0.56 \\
Hung Yen & 33,374 & 32,433 & -941 & -2.81 \\
Hai Duong & 58,464 & 56,449 & -2015 & -3.44 \\
Ha Nam & 31,270 & 33,451 & 2181 & 6.97 \\
Total & $\mathbf{5 2 9 , 6 6 7}$ & $\mathbf{5 4 2 , 2 1 1}$ & $\mathbf{1 2 , 5 4 4}$ & $-\mathbf{2 . 3 7}$ \\
\hline
\end{tabular}




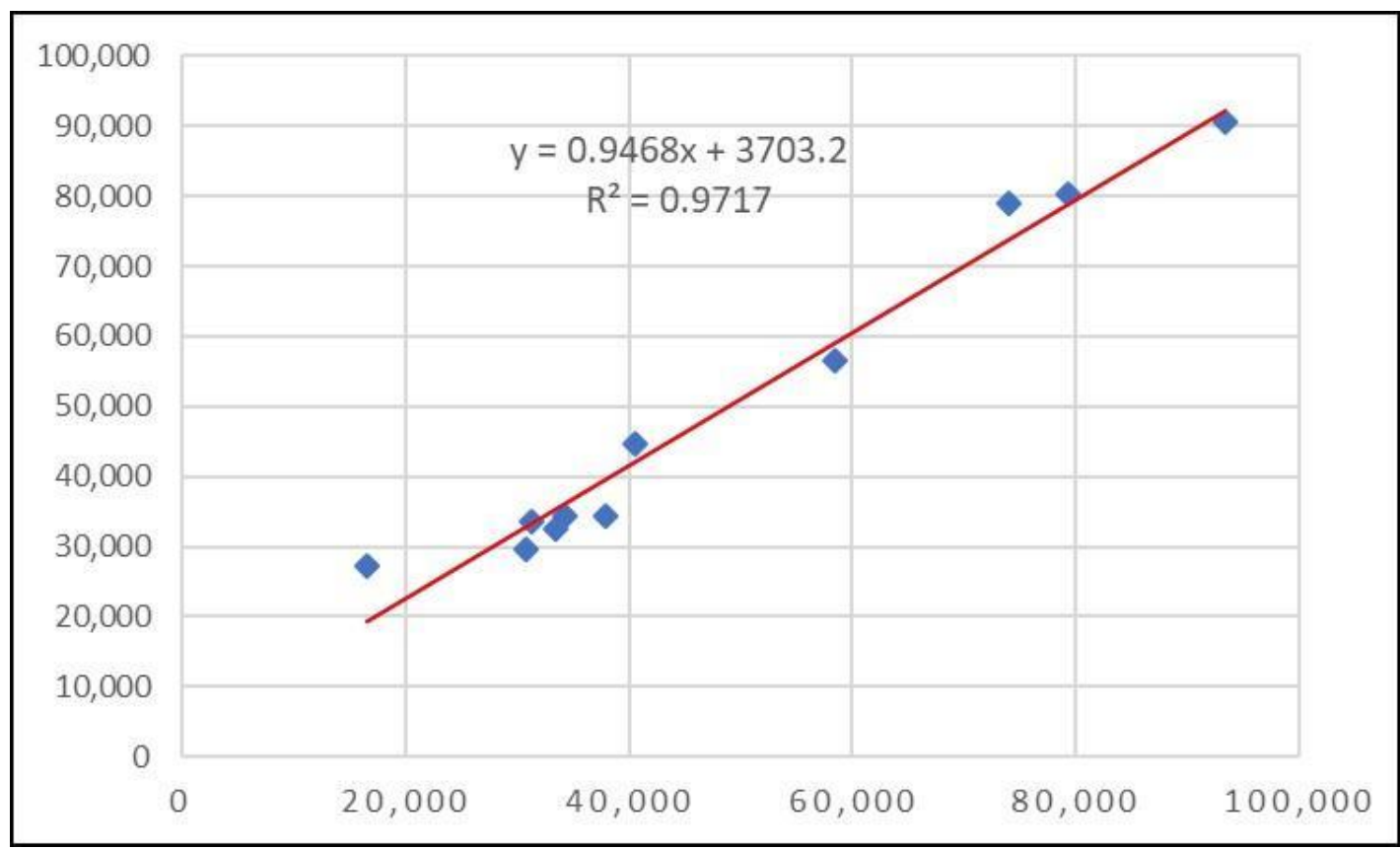

Figure 6. Correlation coefficient of estimated rice area to GSO statistics at province level in the RRD.

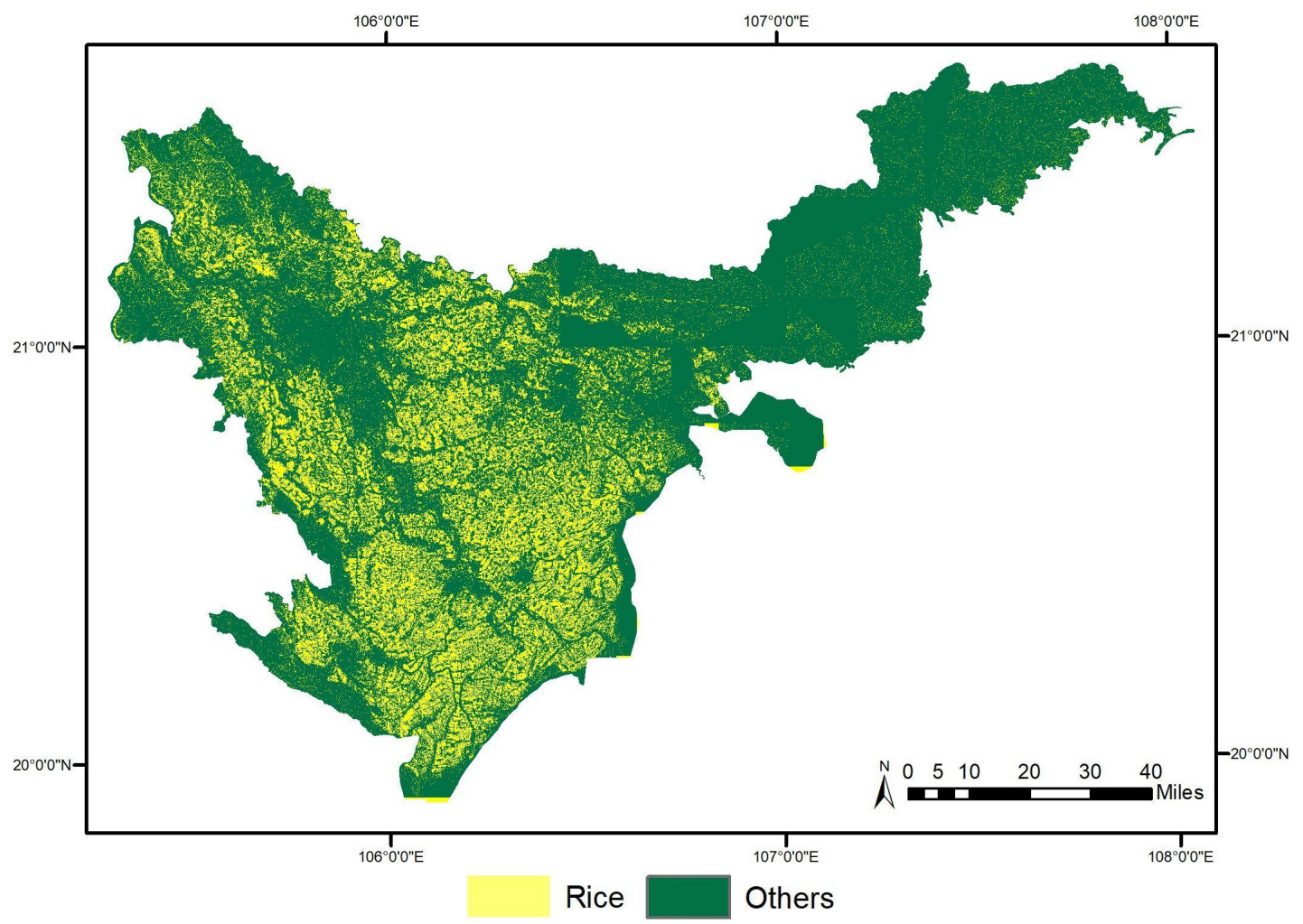

Figure 7. Rice map of winter-spring season in 2018 in the RRD region.

Moreover, a comparison of our results with other studies in the RRD was conducted and is shown in Table 7. Most of the previous studies did not consider Quang Ninh province. Unlike other provinces in the region, Quang Ninh has a high and hilly terrain, which should affect the rice classification model more than most of the remaining provinces with the lower terrains. In comparison to the statistics, our rice map difference is 1879 ha which corresponds to $0.3 \%$ in total if excluding Quang Ninh province, since the largest error of about 10,665 ha was reported above. Besides, our rice area estimation difference compared to the statistics was more positive than the available studies in the 
RRD [29,30,33] (see Table 7). For SAR data, Duy et al. reported that the maximum planted area for all seasons in 5 years from 2007 to 2011 for 10 provinces excluding Quang Ninh with a total difference compared to the statistical database of 67,500 hectares (from 900 hectares to 20,400 hectares) [33]. In the study, rice maps were derived from Envisat ASAR Wide Swath (WS) data using a threshold-based approach with an OA of 83.9\%. In 2016, Lasko et al. employed an RF classifier to produce a rice map from S1A imagery for 5 provinces in the RRD (i.e., Vinh Yen, Hung Yen, Bac Ninh, Ha Noi, Ha Nam) with the maximum OA of $93.5 \%$ with VVVH feature [30]. The estimated rice area reported in the study is 216,784 hectares for 2016, which is about 18,916 hectares of difference in comparison to GSO statistics. Regarding optical satellite images, Landsat 8 was used with the XGBoost classifier to obtain a rice map for the RRD in 4 years from 2013 to 2016 excluding Quang Ninh [29]. The rice maps in the study were underestimated in the statistics (38,216-80,554 hectares from 2013 to 2016). Despite the high accuracy $(89.42 \%-91.53 \%$ of OA), the difference is still large, especially for the rice map in 2016 . It can be seen that the accuracy of the rice map strongly depends on the training and test datasets.

The GSO statistical data should be a common dataset to evaluate different algorithm performances. Besides, the ML approach has proved its effectiveness compared to the traditional threshold-based method. For different machine learning strategies, such as ensemble learning (i.e., RF in Reference [30]) and SVM in our study, $10 \mathrm{~m}$ resolution of VVVH gives the best results for rice classification in the RRD. However, to conclude that the ML method is more optimal than thresholding technique, it is necessary to assess the same data set. In our study, the SVM classifier was selected based on the experimental results of some previous rice classifications, the effectiveness of the SVM classifier in binary classification problems and its convenient deployment with the Python programming language and Scikit-learn library. As a result, our rice map was created for the winter-spring season in the RRD region including 11 provinces from the time-series S1A data. The OA is $90.50 \%$ with a difference of 12,544 hectares to the GSO statistics. The detailed comparison is listed in Table 7.

Table 7. A comparison of rice area estimated from related studies in the RRD. QN, VP, HY, BN, HN1, HN2 are abbreviated for Quang Ninh, Vinh Phuc, Hung Yen, Bac Ninh, Ha Noi and Ha Nam, respectively.

\begin{tabular}{|c|c|c|c|c|c|c|c|c|}
\hline Source & Year & Study Area & Data Type & Mapped Data (ha) & Statistical Data (ha) & Diff(ha) & Method & $\mathrm{OA}(\%)$ \\
\hline \multirow{3}{*}{ [29] } & 2013 & \multirow{3}{*}{ RRD excludes QN } & \multirow{3}{*}{ Optical } & 550,100 & 594,524 & 44,424 & \multirow{3}{*}{ XGBoost } & 91.53 \\
\hline & 2014 & & & 546,600 & 593,706 & 47,106 & & 90.74 \\
\hline & 2015 & & & 542,100 & 580,361 & 38,216 & & 90.48 \\
\hline$[30]$ & 2016 & VP. HY. BN. HN1. HN2 & SAR & 216,784 & 235,700 & 18,916 & RF & 93.50 \\
\hline [33] & 2007-2011 & RRD excludes QN & SAR & $1,182,600$ & $1,115,100$ & 67,500 & Threshold-based & 83.90 \\
\hline Ours & 2018 & RRD & SAR & 542,211 & 529,667 & 12,544 & SVM & 90.50 \\
\hline
\end{tabular}

\subsection{Permanent Water Mapping}

The permanent water surface will slightly change over the years due to human impacts on rivers, lakes and aquaculture areas. In order to obtain flood maps more accurately, we created a permanent water map for 2018 (Figure 8a). The permanent water surface was then excluded to get a temporal water map which might be caused by flooding.

For different study areas, VV and VH data result in different efficiencies for water detection because of different environmental conditions such as windy and calm. Since both VV [61,71] and $\mathrm{VH}[72,73]$ are proved to be good at detecting water, we conducted a further experiment in the RRD region. We found that $\mathrm{VV}$ is better at detecting permanent water surface areas than both $\mathrm{VH}$ data and $\mathrm{VV}+\mathrm{VH}$ data. Meanwhile, $\mathrm{VH}$ data is better in the detection of submerged rice areas. Figure $8 \mathrm{~b}, \mathrm{c}$ are the VV-derived and VH-derived permanent water maps, respectively. It shows that the water map derived from VV has a smoother surface than the one derived from VH data. Besides, VH data is not capable of detecting small canals.

The permanent water validation results on the test data are shown in Tables 8 and 9. The water map has a fairly high accuracy of $\mathrm{OA}=90.94 \%$ on the test data. However, the precision of the water 
class (0.8) indicates that the water map has not yet detected certain water areas. By visual inspection, we observed that some small canals, located in metropolitan areas with curving footprints, were often misclassified because near-shore pixels might not be pure water pixels (Figure 9a). In some cases, these small canals could be in the dry season (Figure 9b) or could be covered by vegetation (Figure 9c,d). However, this does not often happen in the aquaculture areas, as they are usually distributed side by side. These canals typically have a flow width from 10 to $40 \mathrm{~m}$, so pure water pixels in the center of the stream might be removed by the opening process in our morphological transformation step. Besides, the Otsu approach, which is sensitive to the global distribution of the target and background classes [74] and high spatial resolution of S1A data (i.e., $10 \mathrm{~m}$ ), had created a misclassification of the permanent water map for the RRD in 2018. Similar issues have also been pointed out in previous studies [36,39].

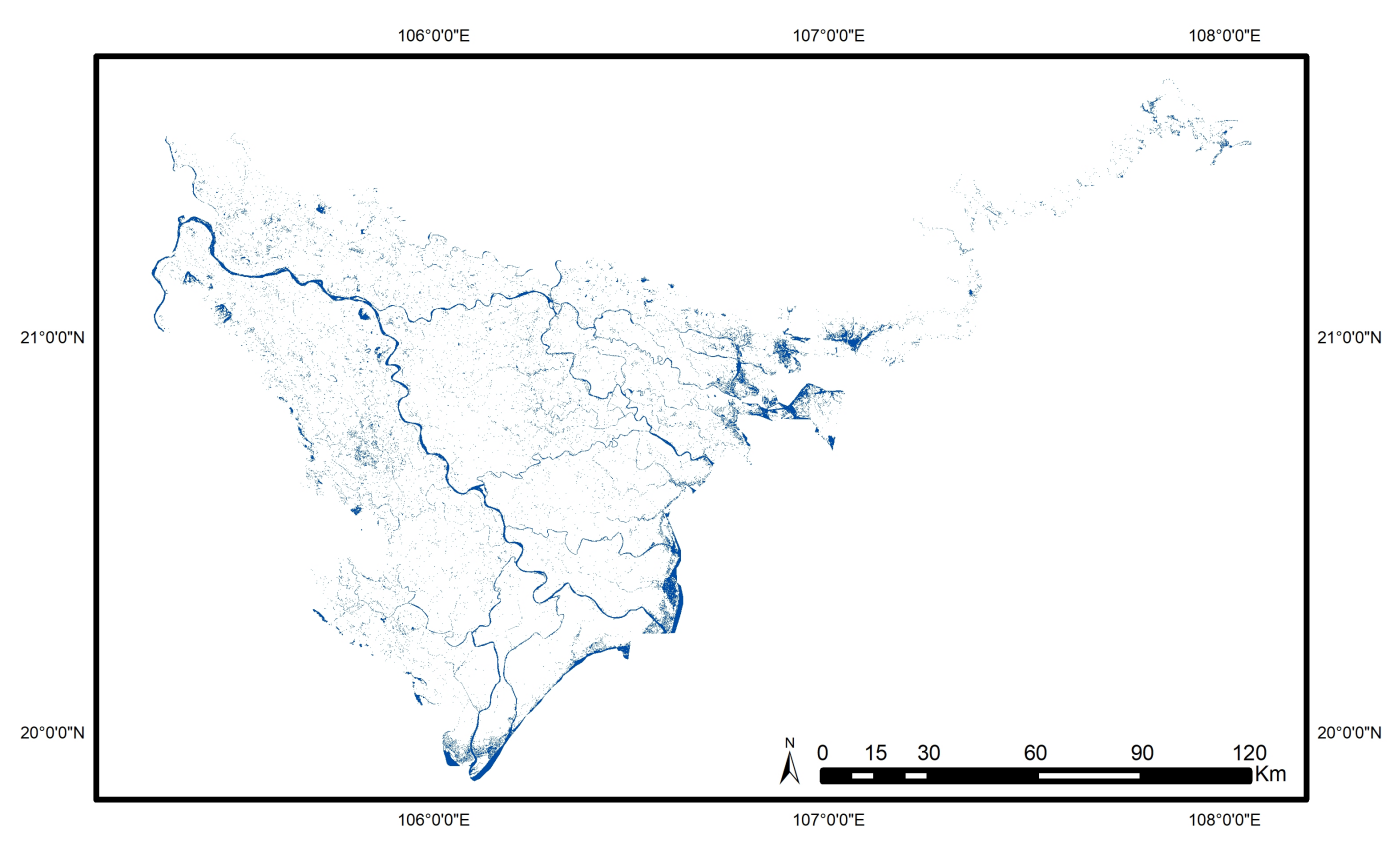

(a)

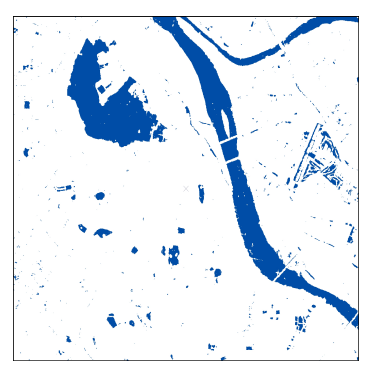

(b)

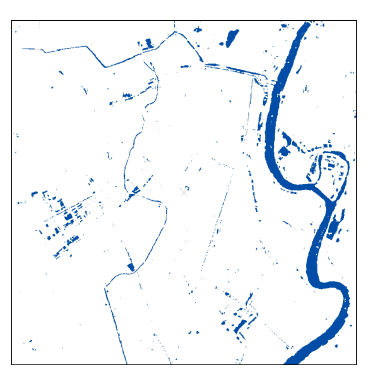

Others

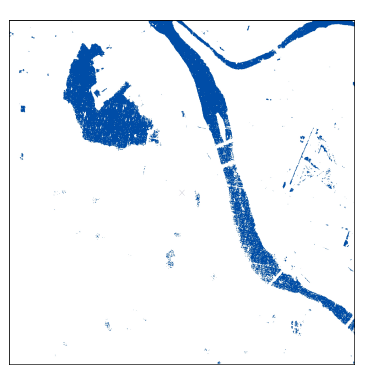

(c)

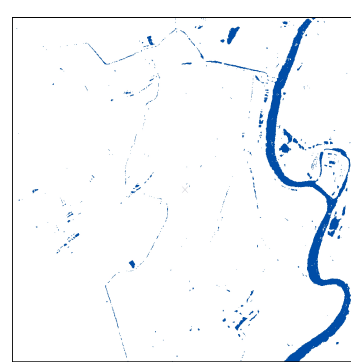

Permanent water

Figure 8. The permanent water map estimated from VV data for the RRD in 2018 (a) and Specified scenes of permanent water derived from VV data (b) and VH data (c). 


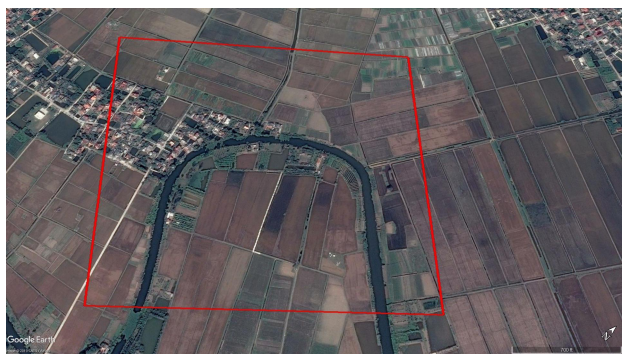

(a) A curve flow $20 \mathrm{~m}$ width.

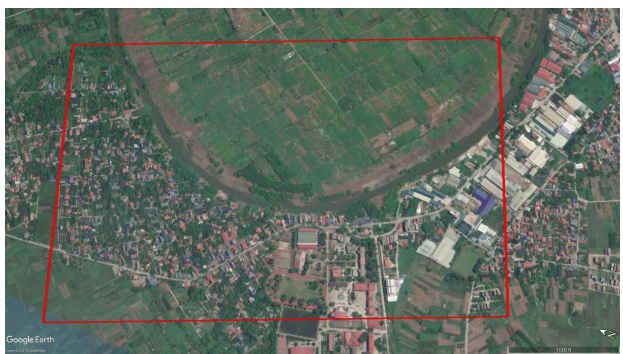

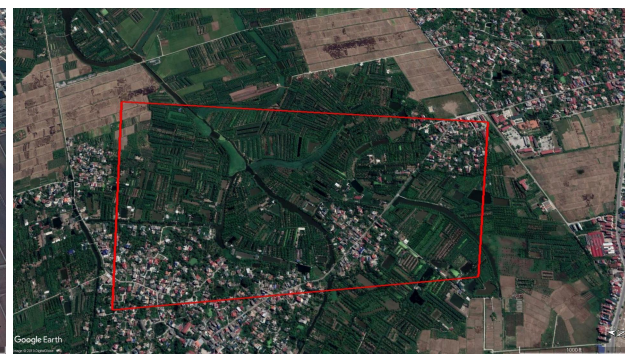

(b) A flow $21 \mathrm{~m}$ width in a dry season.

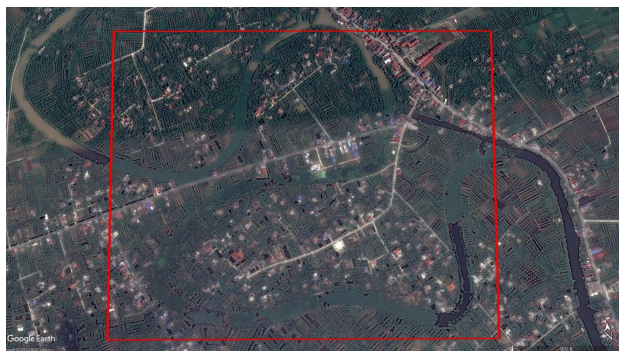

(c) A flow $20 \mathrm{~m}$ width covered by vegetation. (d) A flow $33 \mathrm{~m}$ width covered by vegetation.

Figure 9. Some typical cases of misclassified water regions.

Table 8. Results of water map assessment with inspection data.

\begin{tabular}{cccc}
\hline OA(\%) & F1-Water & F1-Non-Water & Kappa \\
\hline 90.94 & 0.88 & 0.93 & 0.81 \\
\hline
\end{tabular}

Table 9. Precision and recall of permanent water extraction model.

\begin{tabular}{ccc}
\hline Measures & Water & Non-Water \\
\hline Precision & 0.80 & 0.99 \\
Recall & 0.98 & 0.87 \\
\hline
\end{tabular}

\subsection{Submerged Rice Area Estimation}

The tropical storm Son-Tinh landed around 19 July 2018, accompanied by heavy rain, causing serious flooding. So, temporal water maps for three days afterwards using S1A images available on 22 July 2018 (Figure 10a), 3 August 2018 (Figure 10b), and 15 August 2018 (Figure 10c) were created. The affected rice map was produced by stacking temporal water and rice maps together. It can be seen that most of the rice-growing areas were inundated during the stormy period, which is shown in Figure 10a. Depending on the terrain and weather conditions, rice in areas with rapid drainage will be able to recover after storms. However, for areas with long-term inundation, rice will have less resilience and could be considered damaged rice (Figure 10b,c). The flood occurred during the storm Son-Tinh mainly in agricultural areas. Submerged rice maps and flood maps are quite similar because rice is the main agricultural crop in the region. The GSO reported serious rice damages by flooding at the locality at different times (i.e., 21 July 2018 in Bac Ninh, 29 August 2018 in Thai Binh, 23 August 2018 in Ha Noi, 8 August 2018 in Nam Dinh and 3 August 2018 in Ninh Binh). We relied on the statistical report's dates to make a comparison of affected rice from our estimation. The corresponding S1A flood maps on 22 July 2018 for Bac Ninh and Nam Dinh, on 15 August 2018 for Thai Binh and Hanoi, and on 3 August 2018 for Ninh Binh, were created. 
(a) 22 July 2018
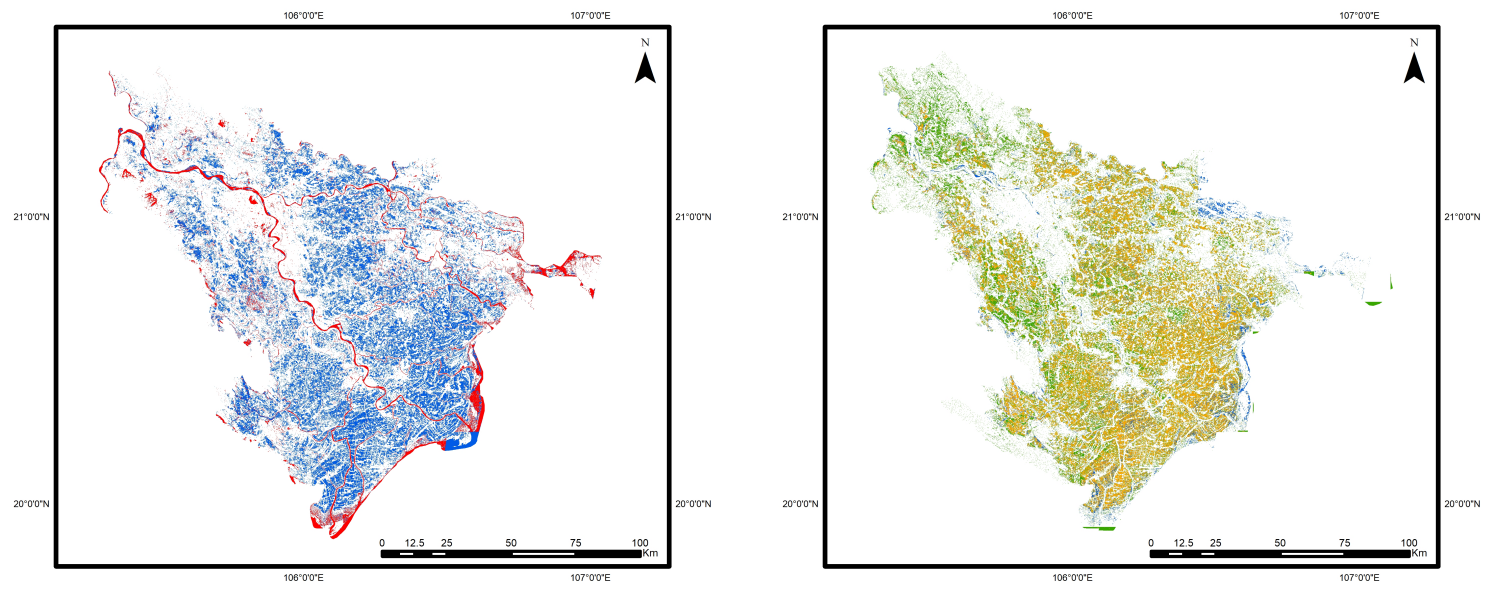

(b) 3 August 2018
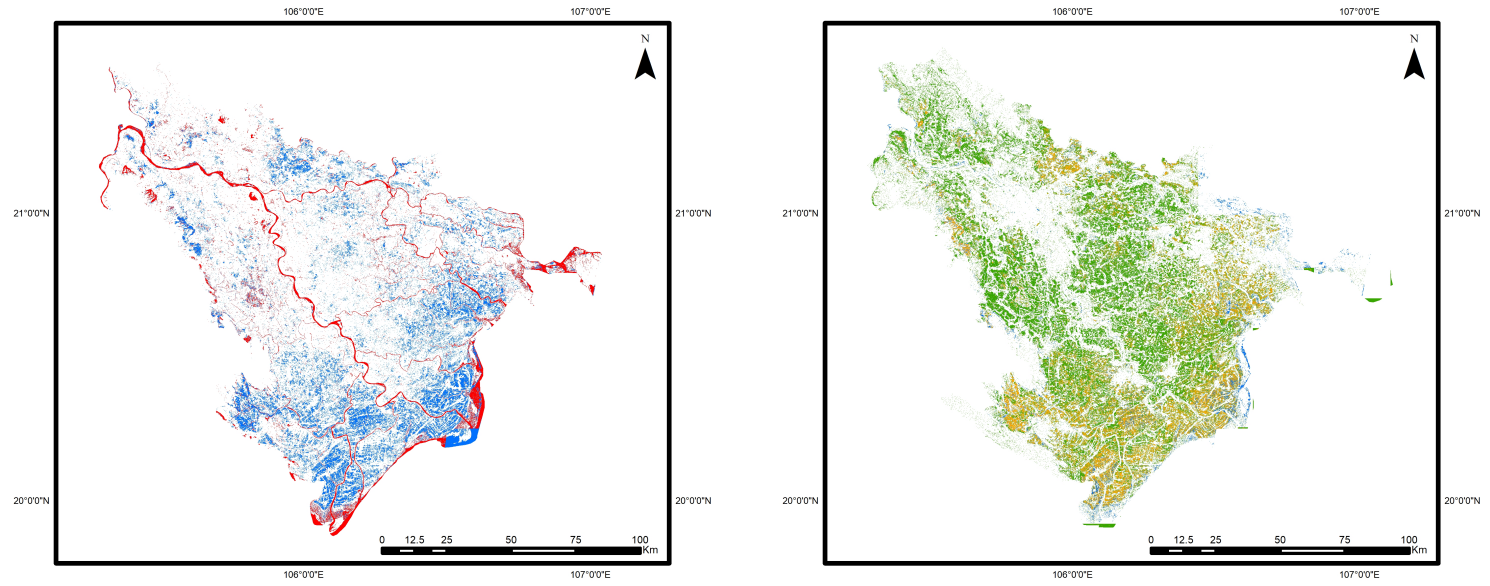

(c) 15 August 2018
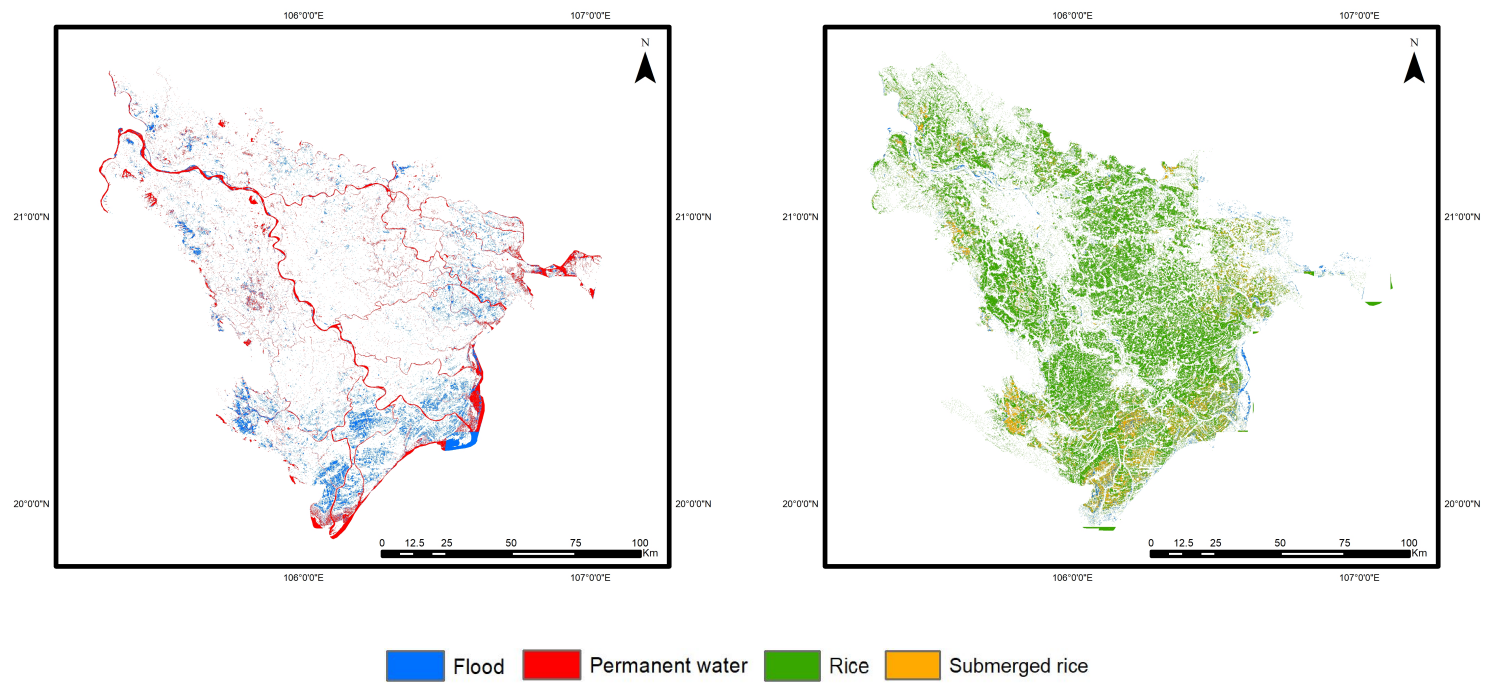

Figure 10. Visualization of flood map with permanent water map (left column) and rice map with submerged rice map (right column) on 22 July 2018, 3 August 2018 and 15 August 2018, for 10 provinces in the RRD. 
For Tien Du, Thuan Thanh and Luong Tai districts in Thai Binh province, the differences between the affected rice area and the statistics were 1519 ha, 1114 ha, 1375 ha, respectively. For Tien Hai, Thai Thuy and Kien Xuong districts, the total difference was less than 2676 ha. In Hanoi and Ninh Binh, estimations were higher than the statistics of 4086 hectares and 6611 hectares. In Nam Dinh, the largest difference was observed at 19,866 hectares (Table 10). In general, the affected rice area from S1A data tended to be larger than statistical reports. The GSO surveyed and made reports after the storm. Besides, the fieldwork had many difficulties due to bad weather conditions, those may cause errors in estimation. Otherwise, fast assessment of affected rice areas caused by flooding from remote sensing will yield immediate and convincing results.

Table 10. Comparison of affected rice area reported by GSO statistics our proposed method.

\begin{tabular}{|c|c|c|c|c|c|}
\hline Location & Mapped Data (ha) & Affected Rice Map Date & Statistical Data (ha) & Reported Date & Diff (ha) \\
\hline Thuan Thanh & 4014 & 22 July 2018 & 2900 & 21 July 2018 & 1114 \\
\hline Tien Hai & 2379 & & & 29 August 2018 & $<2676$ \\
\hline Thai Thuy & 411 & 15 August 2018 & $>2000$ & & \\
\hline Kien Xuong & 1886 & & & & \\
\hline Nam Dinh & 38,373 & 3 August 2018 & 31,762 & Before 8 August 2018 & 6611 \\
\hline Ninh Binh & 26,797 & 22 July 2018 & 6931 & 3 August 2018 & 19,866 \\
\hline
\end{tabular}

The affected rice maps of the RRD on 22 July 2018, 3 August 2018, and 15 August 2018, were created to evaluate rice damage levels. The affected rice area decreased over time depending on local drainage conditions. As can be seen in Table 11, about of 260,971 hectares of rice were inundated directly after the storm made its landfall on 22 July. The inundated area was reduced to 142,054 hectares and 57,343 hectares on 3 August 2018 and 15 August 2018 for 10 provinces in the RRD, respectively. Long-term flooding made rice waterlogged and then the rice needed to be re-cultivated in some areas. As of 15 August 2018, almost one month after the storm, there was still about 57,343 hectares (10.6\%) of rice remaining inundated in the RRD which was mostly in Hai Phong (7773 ha), Ha Noi (6411 ha), Nam Dinh (17,514 ha), Ninh Binh (12,578 ha), and Thai Binh (5315 ha). In these areas, rice might be completely damaged and replanted. In Ha Nam, Hung Yen, Vinh Phuc and Bac Ninh, the inundated rice areas are smaller than 3000 ha on 15 August 2018. It may be due to their higher elevations and better drainage systems than other provinces. However, Vinh Phuc, at a high elevation, still has severe flooding which causes serious damage to some areas (rectangle A in Figures 11 and 12). For Quang Ninh, with the RoN of 55, the estimated number is 10,121 hectares and 11,119 hectares on 20 July 2018, and on 1 August 2018, respectively. There are no available data for 13 August 2018.

To assess the extent of flooding impacts not only during the storm, we also produced the affected rice map for the whole summer-autumn season using nine S1A images and stacked them up to create flood frequency maps for the rice area (Figure 11). Flood frequency maps will help to visually assess severely affected rice areas and future flooding risk. Areas with a high frequency of flooding ( $>5$ times) will be considered seriously damaged rice areas while areas with a flood frequency of 4 to 5 times are vulnerable by flooding in the future. Some areas such as Lap Thach, Vinh Phuc (Figure 11, A rectangle), Chuong My, Quoc Oai, Hanoi (Figure 11, B rectangle), Nho Quan, Ninh Binh (Figure 11, C rectangle) and Nam Dinh (Figure 11, D rectangle) have the highest flooding risk. Those regions were reported as serious flooding areas with largely damaged rice areas and human life lost during the Son-Tinh storm. Figure 12 illustrates the high correspondence between the rice-flood frequency map and the actual flooding areas in Lap Thach, Vinh Phuc. 
Table 11. Inundated rice area estimation for 10 provinces during the Son-Tinh storm occurrence.

\begin{tabular}{|c|c|c|c|c|c|c|c|}
\hline \multirow{3}{*}{ Province } & \multirow{3}{*}{ Rice Area } & \multicolumn{6}{|c|}{ Affected Rice Area by Flooding Caused by the Son-Tinh Storm Landing in RRD Region } \\
\hline & & \multicolumn{2}{|c|}{22 July 2018} & \multicolumn{2}{|c|}{3 August 2018} & \multicolumn{2}{|c|}{15 August 2018} \\
\hline & & Ha & $\%$ & Ha & $\%$ & Ha & $\%$ \\
\hline Bac Ninh & 34,306 & 23,103 & 67.3 & 10,070 & 29.3 & 1728 & 5 \\
\hline Hai Duong & 56,449 & 3220 & 5.7 & 9031 & 16 & 2709 & 4.8 \\
\hline Hai Phong & 34,355 & 20,087 & 58.4 & 16,832 & 49 & 7773 & 22.6 \\
\hline Ha Nam & 33,451 & 15,912 & 47.5 & 4454 & 13.3 & 515 & 1.5 \\
\hline Ha Noi & 90,675 & 37,961 & 41.8 & 12,069 & 13.3 & 6411 & 7 \\
\hline Hung Yen & 32,433 & 17,385 & 53.6 & 2227 & 6.9 & 404 & 1.2 \\
\hline Nam Dinh & 78,868 & 55,786 & 70.7 & 38,373 & 48.6 & 17,514 & 22.2 \\
\hline Ninh Binh & 44,615 & 26,797 & 60.1 & 23,408 & 52.5 & 12,578 & 28.1 \\
\hline Thai Binh & 80,320 & 55,730 & 69.4 & 23,110 & 28.7 & 5315 & 6.6 \\
\hline Vinh Phuc & 29,574 & 4990 & 16.9 & 2480 & 8.4 & 2396 & 8.1 \\
\hline Quang Ninh & 27,165 & - & - & - & - & - & - \\
\hline Total & 542,211 & 260,971 & 48 & 142,054 & 26 & 57,343 & 10.6 \\
\hline
\end{tabular}

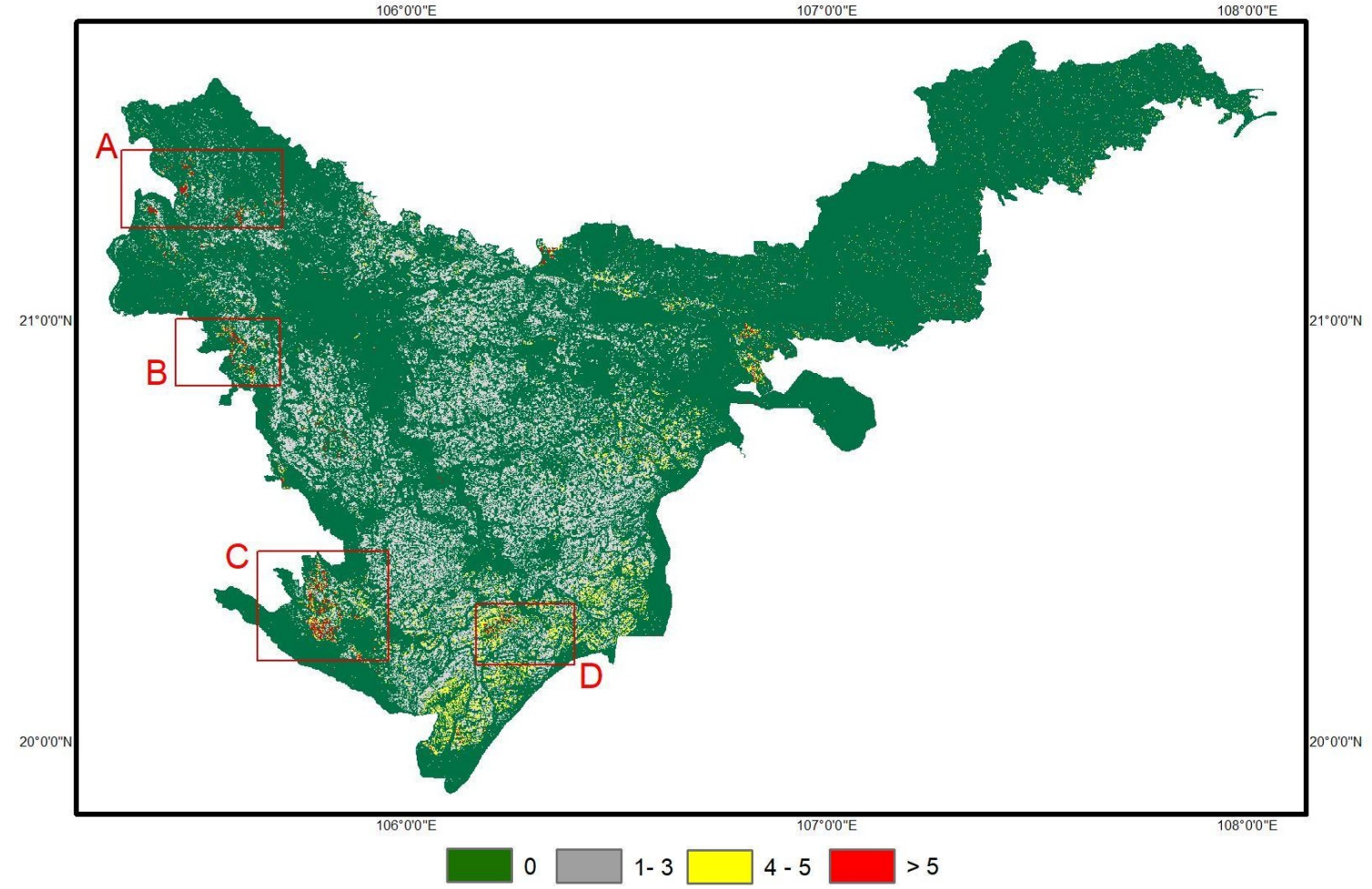

Figure 11. Flood frequency map for summer-autumn rice in 2018. (A) Lap Thach, Vinh Phuc, (B) Chuong My, Quoc Oai, Hanoi, (C) Nho Quan, Ninh Binh, (D) Nam Dinh. 


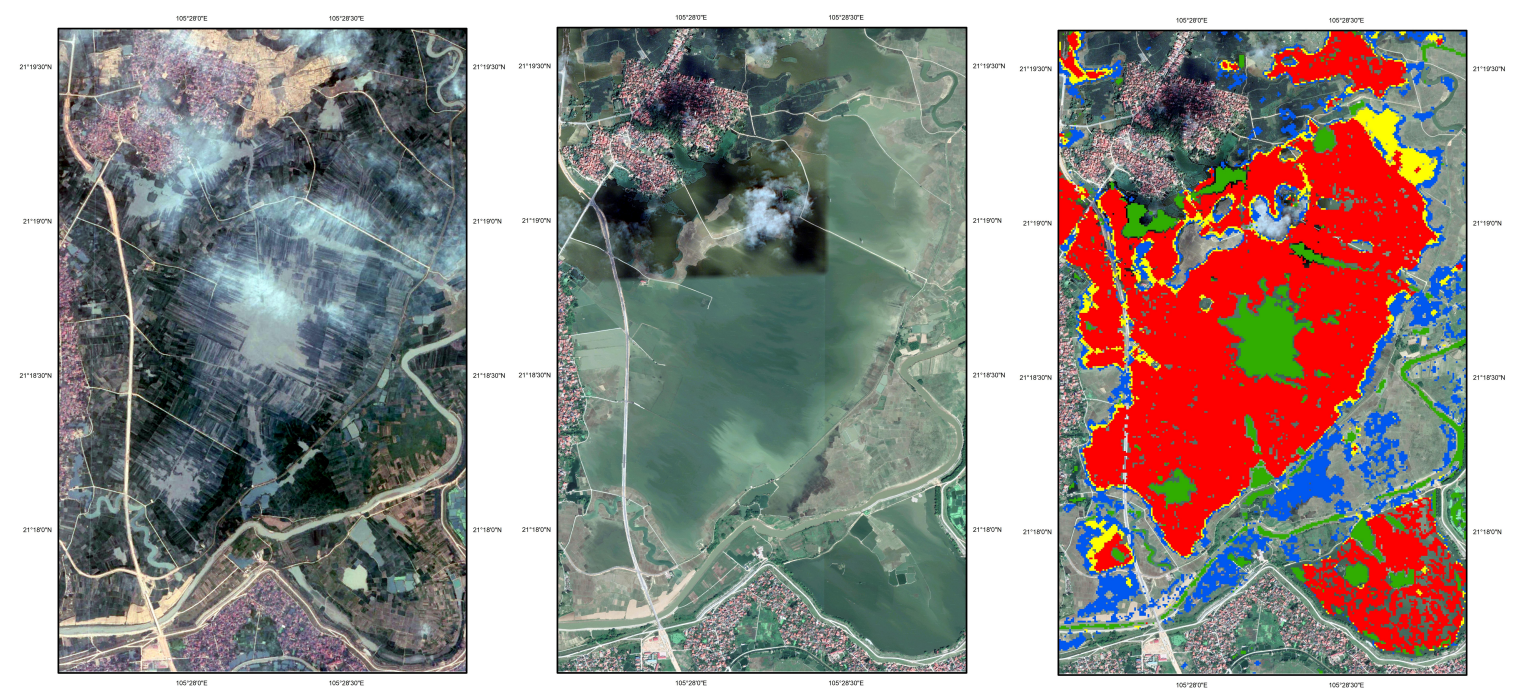

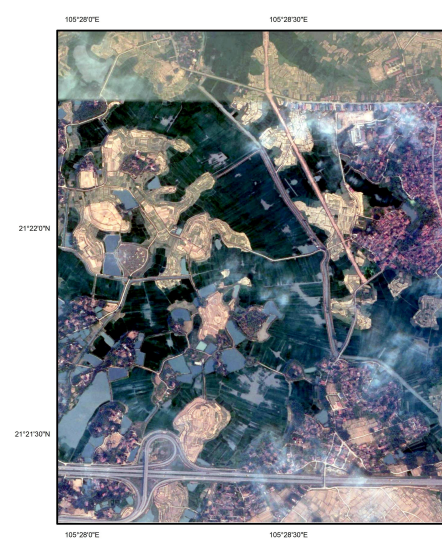

(a) 10 March 2018

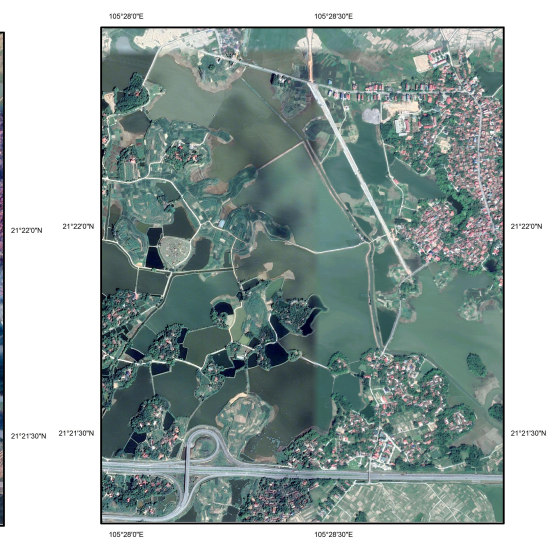

(b) 2 November 2018.

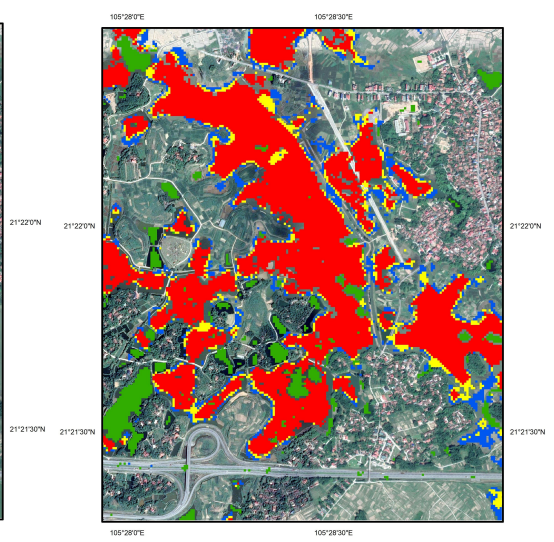

(c) Flood frequency map.

\section{$1-3 \square 4-5 \square>5 \square$ Permanent water}

Figure 12. Visual inspection of heavily affected rice areas caused by prolonged inundation after the storm Son-Tinh in Lap Thach, Vinh Phuc (Figure 11, the A area) after the Son-Tinh happened. Column (a) Two Google Earth image scene on 10 March 2018-(dry season), Column (b) Two Google Earth Image scenes on 2 November 2018, Column (c) A combined scene of flood frequency map and Google Earth image on 2 November 2018 (flooding season).

\section{Conclusions}

Storms and hurricanes from the South China Sea annually land on the mainland and cause serious damage to the RRD from May to October [3], especially during the summer-autumn rice crop. We have addressed and solved the two main remaining problems in previous studies. Firstly, the rice map of all 11 provinces in the RRD area has not been noticed due to the confusion in available administrative maps. Secondly, the use of the S1A images for flood detection and damaged rice assessment by flooding is very limited in this region although the RRD is annually hit by tropical storms, which causes serious damage to rice crops. Moreover, damaged rice statistics are only reported for heavy flooded areas at the end of months. Traditional statistical measurement methods are performed intermittently and inconsistently for rice damage estimation due to extreme environmental conditions, which limited timely responses in areas of high risk.

In this study, we proposed a complete procedure for rice mapping, permanent water mapping, flooding mapping and NRT submerged rice assessment from S1A data. In particular, four datasets 
including VV, VH, VVVH, $\frac{V V-V H}{V V+V H}$ were evaluated with SVM classifier, VVVH was selected to obtain the rice map due to its best performance. Similarly, VV and VH were evaluated and applied with the Otsu thresholding technique for permanent water and NRT flooding extraction, respectively. By stacking all the water body map within the year, the permanent water map was acquired. The permanent water map was then excluded from the temporal water map to obtain the NRT flooding map. After that, a stacked image of the rice map and the NRT flooding map was used to assess submerged areas. Further analysis was carried by the flood frequency map which stacking all the flooded rice maps in the study area. The evaluation of our methodology is based on field data and Vietnamese government statistics.

The experiment was conducted for the assessment of damaged rice areas caused by the Son-Tinh storm which arrived at the RRD around 19 July 2018. The latest RRD rice map in the winter-spring season of 2018 was produced with $90.5 \%$ OA recorded with VVVH data. The permanent water map of the RRD in 2018 was obtained from all the S1A images within the year and also achieved $90.94 \%$ of OA using VV signals. The temporal flood map derived from VH data was created in the period from 22 July to 15 August 2018, to assess the affection of the Son-Tinh storm on the study area. In comparison with the available statistics of GSO for the Son-Tinh damages, our estimation was larger than that of the statistical data. It can be explained by the fact the affected rice area estimation from GSO was not conducted simultaneously, meanwhile, our estimation will yield results earlier than any fieldwork. Based on the experiment, we can quickly report the affected rice areas at the provincial level and the flooding risk map for the Son-Tinh storm.

Some of the limitations encountered during the study can be mentioned, such as the low accuracy of the rice maps of mountainous areas in the Quang Ninh province, the low frequency of S1A over RRD, that is, every 12 days. For NRT flooding detection, the misclassification of small and complex shape canals covered by vegetation and the limitation of GSO validation data. In future, the rice classification model for areas with high terrain will be investigated further. The detection of small canals could be overcome by calculating a local optimal threshold at each small-district-level scene of large images in the RRD. The quick estimation of NRT flooding and damaged rice production should be improved when Sentinel 1B is completed and the updated GSO dataset is available for the RRD region. Finally, when flooding occurs, not only rice but also other crops are affected. The usage of remote sensing to monitor other crops under flooding will be considered.

Author Contributions: Conceptualization, A.P. and T.T.N.N.; Methodology, A.P., C.D.M. and T.T.N.N.; Software, A.P., D.N.H. and C.D.M.; Validation, A.P.; Investigation, A.P. and C.D.M.; Resources, H.Q.B. and T.T.N.N.; Writing-original draft preparation, A.P. and T.T.N.N.; Writing-review and editing, A.P. and T.T.N.N.; Visualization, A.P. and T.T.N.N.; Supervision, C.D.M., T.T.N., H.Q.B. and T.T.N.N.; Project administration, H.Q.B. and T.T.N.N.; Funding acquisition, H.Q.B. and T.T.N.N.

Funding: This work has been supported by Vietnam National University Hanoi (VNU), under Project No. QG.18.36 and Project No. QG.17.41.

Acknowledgments: The authors would like to thank the anonymous reviewers for their time and their thoughtful comments and efforts towards improving our manuscript. The authors would like to thank the European Space Agency for the open data policy of Sentinel 1A data. We also thank General Statistics Office of Vietnam for providing free statistical data.

Conflicts of Interest: The authors declare no conflict of interest.

\section{References}

1. Vietnamese Rice Successfully Conquers 150 Markets and Eyes More-Web Portal Ministry of Industry and Trade. Available online: http://moit.gov.vn/web/web-portal-ministry-of-industry-and-trade/tinchi-tiet/- / chi-tiet/vietnamese-rice-successfully-conquers-150-markets-and-eyes-more-13535-1305.html (accessed on 29 May 2019).

2. FAOSTAT. Top Countries, Export Quantity of Rice 2016. Available online: http://www.fao.org/faostat/en/ \#rankings/countries_by_commodity_exports (accessed on 29 May 2019). 
3. Luu, C.; Von Meding, J.; Kanjanabootra, S. Analysing flood fatalities in Vietnam using national disaster database and tree-based methods. Nat. Hazards Earth Syst. Sci. 2017, 115. [CrossRef]

4. Wang, J.; Hiroshi, I.; Ning, S.; Khujanazarov, T.; Yin, G.; Guo, L. Attribution analyses of impacts of environmental changes on streamflow and sediment load in a mountainous basin, Vietnam. Forests 2016, 7, 30. [CrossRef]

5. Fontenelle, J.P. Water management decentralisation in the Red River Delta, Vietnam: An uncompleted transition process towards local governance. Int. J. Water 2001, 1, 380-396. [CrossRef]

6. Nong, D.H.; Lepczyk, C.A.; Miura, T.; Fox, J.M. Quantifying urban growth patterns in Hanoi using landscape expansion modes and time series spatial metrics. PLoS ONE 2018, 13, e0196940. [CrossRef] [PubMed]

7. NASA Satellite Shows Son-Tinh's Swan Song. Available online: https://www.nasa.gov/feature/goddard/ 2018/ son-tinh-northwestern-pacific-ocean (accessed on 29 May 2019).

8. General Statistics Office of Vietnam. Agriculture, Forestry and Fishing. Available online: https://www.gso. gov.vn/default_en.aspx?tabid=778 (accessed on 29 May 2019).

9. Okamoto, K. Estimation of rice-planted area in the tropical zone using a combination of optical and microwave satellite sensor data. Int. J. Remote Sens. 1999, 20, 1045-1048. [CrossRef]

10. Le Toan, T.; Ribbes, F.; Wang, L.F.; Floury, N.; Ding, K.H.; Kong, J.A.; Fujita, M.; Kurosu, T. Rice crop mapping and monitoring using ERS-1 data based on experiment and modeling results. IEEE Trans. Geosci. Remote Sens. 1997, 35, 41-56. [CrossRef]

11. Zhou, Y.; Xiao, X.; Qin, Y.; Dong, J.; Zhang, G.; Kou, W.; Jin, C.; Wang, J.; Li, X. Mapping paddy rice planting area in rice-wetland coexistent areas through analysis of Landsat 8 OLI and MODIS images. Int. J. Appl. Earth Obs. Geoinf. 2016, 46, 1-12. [CrossRef]

12. Nuarsa, I.W.; Nishio, F.; Hongo, C.; Mahardika, I.G. Using variance analysis of multitemporal MODIS images for rice field mapping in Bali Province, Indonesia. Int. J. Remote Sens. 2012, 33, 5402-5417. [CrossRef]

13. Xiao, X.; Boles, S.; Liu, J.; Zhuang, D.; Frolking, S.; Li, C.; Salas, W.; Moore, B., III. Mapping paddy rice agriculture in southern China using multi-temporal MODIS images. Remote Sens. Environ. 2005, 95, 480-492. [CrossRef]

14. Xiao, X.; Boles, S.; Frolking, S.; Li, C.; Babu, J.Y.; Salas, W.; Moore, B., III. Mapping paddy rice agriculture in South and Southeast Asia using multi-temporal MODIS images. Remote Sens. Environ. 2006, 100, 95-113. [CrossRef]

15. Manfron, G.; Crema, A.; Boschetti, M.; Confalonieri, R. Testing automatic procedures to map rice area and detect phenological crop information exploiting time series analysis of remote sensed MODIS data. In Proceedings of the SPIE Remote Sensing for Agriculture, Ecosystems, and Hydrology XIV, Edinburgh, UK, 24-27 September 2012; Volume 8531, p. 85311E.

16. Hoang, H.K.; Bernier, M.; Duchesne, S.; Tran, Y.M. Rice mapping using RADARSAT-2 dual-and quad-pol data in a complex land-use Watershed: Cau River Basin (Vietnam). IEEE J. Sel. Top. Appl. Earth Obs. Remote Sens. 2016, 9, 3082-3096. [CrossRef]

17. Li, Q.; Zhang, H.; Du, X.; Wen, N.; Tao, Q. County-level rice area estimation in southern China using remote sensing data. J. Appl. Remote Sens. 2014, 8, 083657. [CrossRef]

18. Park, S.; Im, J.; Park, S.; Yoo, C.; Han, H.; Rhee, J. Classification and mapping of paddy rice by combining Landsat and SAR time series data. Remote Sens. 2018, 10, 447. [CrossRef]

19. Tian, H.; Wu, M.; Wang, L.; Niu, Z. Mapping early, middle and late rice extent using sentinel-1A and Landsat-8 data in the poyang lake plain, China. Sensors 2018, 18, 185. [CrossRef] [PubMed]

20. Mandal, D.; Kumar, V.; Bhattacharya, A.; Rao, Y.S.; Siqueira, P.; Bera, S. Sen4rice: A processing chain for differentiating early and late transplanted rice using time-series Sentinel-1 SAR data with Google Earth Engine. IEEE Geosci. Remote Sens. Lett. 2018, 12, 1947-1951. [CrossRef]

21. Clauss, K.; Yan, H.; Kuenzer, C. Mapping paddy rice in China in 2002, 2005, 20102014 MODIS Time Ser. Remote Sens. 2016, 8, 434. [CrossRef]

22. Torbick, N.; Chowdhury, D.; Salas, W.; Qi, J. Monitoring rice agriculture across myanmar using time series Sentinel-1 assisted by Landsat-8 and PALSAR-2. Remote Sens. 2017, 9, 119. [CrossRef]

23. Sakamoto, T.; Van Phung, C.; Kotera, A.; Nguyen, K.D.; Yokozawa, M. Analysis of rapid expansion of inland aquaculture and triple rice-cropping areas in a coastal area of the Vietnamese Mekong Delta using MODIS time-series imagery. Landsc. Urban Plan. 2009, 92, 34-46. [CrossRef] 
24. Son, N.T.; Chen, C.F.; Chen, C.R.; Duc, H.N.; Chang, L.Y. A phenology-based classification of time-series MODIS data for rice crop monitoring in Mekong Delta, Vietnam. Remote Sens. 2014, 6, 135-156. [CrossRef]

25. Kontgis, C.; Schneider, A.; Ozdogan, M. Mapping rice paddy extent and intensification in the Vietnamese Mekong River Delta with dense time stacks of Landsat data. Remote Sens. Environ. 2015, 169, 255-269. [CrossRef]

26. Bouvet, A.; Le Toan, T. Use of ENVISAT/ASAR wide-swath data for timely rice fields mapping in the Mekong River Delta. Remote Sens. Environ. 2011, 115, 1090-1101. [CrossRef]

27. Nguyen, D.; Clauss, K.; Cao, S.; Naeimi, V.; Kuenzer, C.; Wagner, W. Mapping rice seasonality in the Mekong Delta with multi-year Envisat ASAR WSM data. Remote Sens. 2015, 7, 15868-15893. [CrossRef]

28. Torbick, N.; Salas, W.; Chowdhury, D.; Ingraham, P.; Trinh, M. Mapping rice greenhouse gas emissions in the Red River Delta, Vietnam. Carbon Manag. 2017, 8, 99-108. [CrossRef]

29. Chuc, M.D.; Anh, N.H.; Thuy, N.T.; Hung, B.Q.; Thanh, N.T.N. Paddy rice mapping in red river delta region using landsat 8 images: Preliminary results. In Proceedings of the 2017 9th International Conference on Knowledge and Systems Engineering (KSE), Hue, Vietnam, 19-21 October 2017; pp. 209-214.

30. Lasko, K.; Vadrevu, K.P.; Tran, V.T.; Justice, C. Mapping double and single crop paddy rice with Sentinel-1A at varying spatial scales and polarizations in Hanoi, Vietnam. IEEE J. Sel. Top. Appl. Earth Obs. Remote Sens. 2018, 11, 498-512. [CrossRef] [PubMed]

31. Hoang, K.H.; Bernier, M.; Duchesne, S.; Tran, M.Y. Classification of rice fields in a complex land-use watershed in Northern Vietnam using RADARSAT-2 data. In Proceedings of the 2014 IEEE Geoscience and Remote Sensing Symposium, Quebec City, QC, Canada, 13-18 July 2014; pp. 1501-1503.

32. Clauss, K.; Ottinger, M.; Kuenzer, C. Mapping rice areas with Sentinel-1 time series and superpixel segmentation. Int. J. Remote Sens. 2018, 39, 1399-1420. [CrossRef]

33. Nguyen, D.; Wagner, W.; Naeimi, V.; Cao, S. Rice-planted area extraction by time series analysis of ENVISAT ASAR WS data using a phenology-based classification approach: A case study for Red River Delta, Vietnam. Int. Arch. Photogramm. Remote Sens. Spat. Inf. Sci. 2015, 40, 77. [CrossRef]

34. Policelli, F.; Slayback, D.; Brakenridge, B.; Nigro, J.; Hubbard, A.; Zaitchik, B.; Carroll, M.; Jung, H. The NASA global flood mapping system. In Remote Sensing of Hydrological Extremes; Springer: Berlin, Germany, 2017; pp. 47-63.

35. De Groeve, T.; Kugler, Z.; Brakenridge, G.R. Near real time flood alerting for the global disaster alert and coordination system. In Proceedings ISCRAM2007; VUBPRESS Brussels University Press, Brussel, Belgium, 2006; pp. 33-39.

36. Martinis, S.; Twele, A.; Voigt, S. Towards operational near real-time flood detection using a split-based automatic thresholding procedure on high resolution TerraSAR-X data. Nat. Hazards Earth Syst. Sci. 2009, 9, 303-314. [CrossRef]

37. Mason, D.C.; Davenport, I.J.; Neal, J.C.; Schumann, G.J.P.; Bates, P.D. Near real-time flood detection in urban and rural areas using high-resolution synthetic aperture radar images. IEEE Trans. Geosci. Remote Sens. 2012, 50, 3041-3052. [CrossRef]

38. Kuenzer, C.; Guo, H.; Huth, J.; Leinenkugel, P.; Li, X.; Dech, S. Flood mapping and flood dynamics of the Mekong Delta: ENVISAT-ASAR-WSM based time series analyses. Remote Sens. 2013, 5, 687-715. [CrossRef]

39. Chini, M.; Hostache, R.; Giustarini, L.; Matgen, P. A hierarchical split-based approach for parametric thresholding of SAR images: Flood inundation as a test case. IEEE Trans. Geosci. Remote Sens. 2017, 55, 6975-6988. [CrossRef]

40. Kotera, A.; Nagano, T.; Hanittinan, P.; Koontanakulvong, S. Assessing the degree of flood damage to rice crops in the Chao Phraya delta, Thailand, using MODIS satellite imaging. Paddy Water Environ. 2016, 14, 271-280. [CrossRef]

41. Kwak, Y.; Shrestha, B.B.; Yorozuya, A.; Sawano, H. Rapid damage assessment of rice crop after large-scale flood in the cambodian floodplain using temporal spatial data. IEEE J. Sel. Top. Appl. Earth Obs. Remote Sens. 2015, 8, 3700-3709. [CrossRef]

42. Basha, E.A.; Ravela, S.; Rus, D. Model-based monitoring for early warning flood detection. In Proceedings of the 6th ACM Conference on Embedded Network Sensor Systems, Raleigh, NC, USA, 4-7 November 2008; ACM: New York, NY, USA, 2008; pp. 295-308. 
43. Rennó, C.D.; Nobre, A.D.; Cuartas, L.A.; Soares, J.V.; Hodnett, M.G.; Tomasella, J.; Waterloo, M.J. HAND, a new terrain descriptor using SRTM-DEM: Mapping terra-firme rainforest environments in Amazonia. Remote Sens. Environ. 2008, 112, 3469-3481. [CrossRef]

44. Nobre, A.D.; Cuartas, L.A.; Hodnett, M.; Rennó, C.D.; Rodrigues, G.; Silveira, A.; Waterloo, M.; Saleska, S. Height Above the Nearest Drainage-a hydrologically relevant new terrain model. J. Hydrol. 2011, 404, 13-29. [CrossRef]

45. Tehrany, M.S.; Pradhan, B.; Jebur, M.N. Flood susceptibility mapping using a novel ensemble weights-of-evidence and support vector machine models in GIS. J. Hydrol. 2014, 512, 332-343. [CrossRef]

46. Mojaddadi, H.; Pradhan, B.; Nampak, H.; Ahmad, N.; Ghazali, A.H.B. Ensemble machine-learning-based geospatial approach for flood risk assessment using multi-sensor remote-sensing data and GIS. Geomat. Nat. Hazards Risk 2017, 8, 1080-1102. [CrossRef]

47. Tehrany, M.S.; Pradhan, B.; Mansor, S.; Ahmad, N. Flood susceptibility assessment using GIS-based support vector machine model with different kernel types. Catena 2015, 125, 91-101. [CrossRef]

48. Ireland, G.; Volpi, M.; Petropoulos, G. Examining the capability of supervised machine learning classifiers in extracting flooded areas from Landsat TM imagery: A case study from a Mediterranean flood. Remote Sens. 2015, 7, 3372-3399. [CrossRef]

49. Rokni, K.; Ahmad, A.; Selamat, A.; Hazini, S. Water feature extraction and change detection using multitemporal Landsat imagery. Remote Sens. 2014, 6, 4173-4189. [CrossRef]

50. Huang, X.; Wang, C.; Li, Z. A near real-time flood-mapping approach by integrating social media and post-event satellite imagery. Ann. GIS 2018, 24, 113-123. [CrossRef]

51. Rosser, J.F.; Leibovici, D.; Jackson, M. Rapid flood inundation mapping using social media, remote sensing and topographic data. Nat. Hazards 2017, 87, 103-120. [CrossRef]

52. Amitrano, D.; Di Martino, G.; Iodice, A.; Riccio, D.; Ruello, G. Unsupervised rapid flood mapping using Sentinel-1 GRD SAR images. IEEE Trans. Geosci. Remote Sens. 2018, 56, 3290-3299. [CrossRef]

53. Notti, D.; Giordan, D.; Caló, F.; Pepe, A.; Zucca, F.; Galve, J. Potential and limitations of open satellite data for flood mapping. Remote Sens. 2018, 10, 1673. [CrossRef]

54. Dao, P.; Liou, Y.A. Object-based flood mapping and affected rice field estimation with Landsat 8 OLI and MODIS data. Remote Sens. 2015, 7, 5077-5097. [CrossRef]

55. Emergency Management Service-Mapping. Available online: https://floodmap.modaps.eosdis.nasa.gov/ (accessed on 30 July 2019).

56. NRT Global Flood Mapping. Available online: https://emergency.copernicus.eu/mapping/list-ofactivations-rapid (accessed on 30 July 2019).

57. Mountrakis, G.; Im, J.; Ogole, C. Support vector machines in remote sensing: A review. ISPRS J. Photogramm. Remote Sens. 2011, 66, 247-259. [CrossRef]

58. Cortes, C.; Vapnik, V. Support-vector networks. Mach. Learn. 1995, 20, 273-297. [CrossRef]

59. Schumann, G.; Di Baldassarre, G.; Alsdorf, D.; Bates, P. Near real-time flood wave approximation on large rivers from space: Application to the River Po, Italy. Water Resour. Res. 2010, 46. [CrossRef]

60. Man, C.D.; Nguyen, T.T.; Bui, H.Q.; Lasko, K.; Nguyen, T.N.T. Improvement of land-cover classification over frequently cloud-covered areas using Landsat 8 time-series composites and an ensemble of supervised classifiers. Int. J. Remote Sens. 2018, 39, 1243-1255. [CrossRef]

61. Liu, C. Analysis of Sentinel-1 SAR Data for Mapping Standing Water in the Twente Region. Master's Thesis, University of Twente, Twente, The Netherlands, February 2016. Available online: http:/ www.itc. nl/library/papers_2016/msc/wrem/cliu.pdf (accessed on 27 August 2019).

62. Baghdadi, N.; El Hajj, M.; Zribi, M.; Bousbih, S. Calibration of the water cloud model at C-band for winter crop fields and grasslands. Remote Sens. 2017, 9, 969. [CrossRef]

63. Otsu, N. A threshold selection method from gray-level histograms. IEEE Trans. Syst. Man, Cybern. 1979, 9, 62-66. [CrossRef]

64. Vincent, L. Morphological Grayscale Reconstruction in Image Analysis: Applications and E cient Algorithms. IEEE Trans. Image Process. 1993, 2, 176-201. [CrossRef] [PubMed]

65. Shuttle Radar Topography Mission 1 Arc-Second Global: SRTM1N22W016V3. Available online: https: / / earthexplorer.usgs.gov/fgdc/8360/SRTM1N22W016V3/ (accessed on 29 May 2019).

66. Flooding Situation in Chuong My. Available online: http://www.antv.gov.vn/tin-tuc/xa-hoi/tinh-hinhngap-lut-tai-chuong-my-244134.html (accessed on 29 May 2019). 
67. Nho Quan Concentrates Forces to Respond to Heavy Rain and Flood. Available online: http:/ / ninhbinh.gov.vn/ubnd-ninhbinh/4/469/39067/96803/Tin-noi-bat/Nho-Quan-tap-trungluc-luong-ung-pho-voi-mua--lu.aspx (accessed on 29 May 2019).

68. Wang, Y.; Hess, L.L.; Filoso, S.; Melack, J.M. Understanding the radar backscattering from flooded and nonflooded Amazonian forests: Results from canopy backscatter modeling. Remote Sens. Environ. 1995, 54, 324-332. [CrossRef]

69. Manavalan, R.; Rao, Y.; Krishna Mohan, B. Comparative flood area analysis of C-band VH, VV, and L-band HH polarizations SAR data. Int. J. Remote Sens. 2017, 38, 4645-4654. [CrossRef]

70. Solbø, S.; Solheim, I. Towards operational flood mapping with satellite SAR. In Proceedings of the 2004 Envisat \& ERS Symposium, Salzburg, Austria, 6-10 September 2004; ESA SP-572, April 2005.

71. Twele, A.; Cao, W.; Plank, S.; Martinis, S. Sentinel-1-based flood mapping: A fully automated processing chain. Int. J. Remote Sens. 2016, 37, 2990-3004. [CrossRef]

72. Xing, L.; Tang, X.; Wang, H.; Fan, W.; Wang, G. Monitoring monthly surface water dynamics of Dongting Lake using Sentinel-1 data at $10 \mathrm{~m}$. PeerJ 2018, 6, e4992. [CrossRef] [PubMed]

73. Duy, N.B. Automatic detection of surface water bodies from Sentinel-1 SAR images using Valley-Emphasis method. Vietnam J. Earth Sci. 2015, 37, 328-343. [CrossRef]

74. Vala, H.J.; Baxi, A. A review on Otsu image segmentation algorithm. Int. J. Adv. Res. Comput. Eng. Technol. (IJARCET) 2013, 2, 387-389.

(C) 2019 by the authors. Licensee MDPI, Basel, Switzerland. This article is an open access article distributed under the terms and conditions of the Creative Commons Attribution (CC BY) license (http:/ / creativecommons.org/licenses/by/4.0/). 